\title{
Generalized State-Plane Analysis of Bidirectional CLLC Resonant Converter
}

\author{
Mohsen Rezayati, Farzad Tahami, Senior Member, IEEE, Jean-Luc Schanen, Senior Member, IEEE, and Benoit \\ Sarrazin, Member, IEEE
}

\begin{abstract}
The CLLC resonant converter is a promising candidate for high efficient, bidirectional power transfer applications such as vehicle-to-grid (V2G) on-board charger and hybrid vehicle DC-DC converter. Nevertheless, the analysis of CLLC still remains challenging because of its complex multiresonant nature and several storage elements. In this paper, a circuit analysis method based on change of variables is presented that maps the state space equations into two decoupled sets of equations. The analyses are carried out in two state-plane coordinate systems, then the results are mapped onto the original region. The proposed method is then used to thoroughly analyze the CLLC resonant converter operating in the continuous conduction mode (CCM). The voltage and current stresses of components, zero voltage switching condition, output voltage gain, output characteristic diagram, and mode boundary of CCM/DCM are then obtained. The accuracy of the proposed approach is verified by the experiments on a $3 \mathrm{~kW}$ bidirectional CLLC resonant converter with GaN transistors as the primary and secondary side switches. The results confirm the accuracy of the proposed state-plane analysis of the CLLC resonant converter operating in either direction of power transferring.
\end{abstract}

Index Terms- resonant converter, state-plane analysis, soft switching, Bidirectional DC-DC converter.

\section{INTRODUCTION}

A s more renewables step in, the ongoing change will be drastic for the electrical grid. The energy sector must find new ways to balance energy production and consumption. Electric vehicle (EV) batteries are by far the most costefficient form of energy storage since they require no additional investments in hardware. Vehicle-to-grid (V2G) is a technology that enables energy to be pushed back to the power grid from the battery of an electric car. V2G operation is possible when then on-board charger of EV is capable for

This work was supported in part by the Iranian National Science Foundation (INSF) under Grant 96016634, and the French National Program "Programme d'investissements d'Avenir, IRT Nanoelec" under Grant ANRI0-AIRT-05.

M. Rezayati is with the Department of Electrical Engineering, Sharif University of Technology, Tehran 11365/8639, Iran, and with University Grenoble Alpes, CNRS, Grenoble INP, G2Elab, 38000 Grenoble, France, as the dual-degree doctoral program (e-mail: mohsen.rezayati@grenoble-inp.fr; mohsen.rezayati@ee.sharif.edu;).

F. Tahami is with the Department of Electrical Engineering, Sharif University of Technology, Tehran 11365/8639, Iran (e-mail: tahami@sharif.edu).

J.-L. Schanen, and B. Sarrazin are with University Grenoble Alpes, CNRS, Grenoble INP, G2Elab, 38000 Grenoble, France (e-mail: jean-luc.schanen@ g2elab.grenoble-inp.fr; benoit.sarrazin@g2elab.grenoble-inp.fr).. bidirectional power flow. The CLLC resonant converter is a promising circuit for bidirectional power conversion in applications such as bidirectional electric vehicle charger and hybrid vehicle DC-DC converter [1-9]. This converter is bidirectional in nature [6] and is an appropriate candidate for future V2G systems which was first proposed in [10]. The converter exhibits the advantage of LLC resonant converter in both power directions [11]. The CLLC resonant converter is superior to the conventional dual active bridge (DAB) converter in terms of efficiency and power density [12].

Nevertheless, this type of resonant converters has to be carefully designed, to provide soft switching and proper control over a wide operating range. The first harmonic approximation (FHA) is a simple analysis method, which only considers the fundamental components of applied voltage and current to the resonant tank [13]. Due to its simplicity, the FHA method is widely used in the analysis and design of CLLC resonant converters [5, 8, 11, 14]. However, the accuracy of this method is deteriorated when the voltage and current of load (i.e. the battery) are widely changed or the converter operates in discontinuous conduction mode (DCM) [15].

Time domain analysis (TDA) or state space analysis (SSA) is a general steady state approach for the exact analysis of resonant converters. In this method, the state space equations of each subinterval are solved and the time domain expressions of state variables are obtained over one switching period. TDA is particularly useful for simulation purpose but it is too complicated to be used for design of a resonant converter with several energy storage elements [16].

A graphical and geometrical method for exact analyzing of the resonant converter is the state-plane analysis where current or voltage of the resonant tank elements is calculated as a function of the other variables and plotted in a $2 \mathrm{D}$ or $3 \mathrm{D}$ diagram [17, 18]. The exact circuit behavior and design criteria in CCM and DCM operation can be obtained using this method $[19,20]$. The analytical equations extracted by state-plane analysis can be used directly in the optimization process to increase accuracy. State-plane analysis has been applied to the converters with two or three resonant elements $[19,21-23]$, but the CLLC resonant converter has five resonance elements (two series capacitor-inductor and one transformer) and state-plane analysis is hard to accomplish. Therefore, most of the researches have been focused on FHA and TDA methods [8, 10-12, 24-29]. 


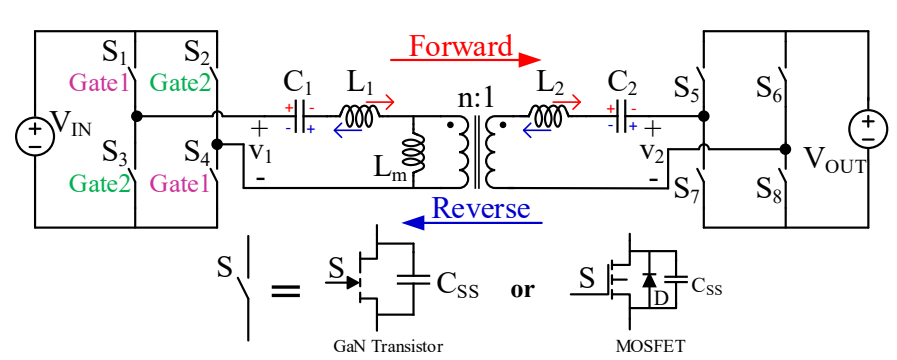

Fig. 1. The bidirectional CLLC resonant converter, (red and blue signs are corresponding to the forward and the reverse power conversion).

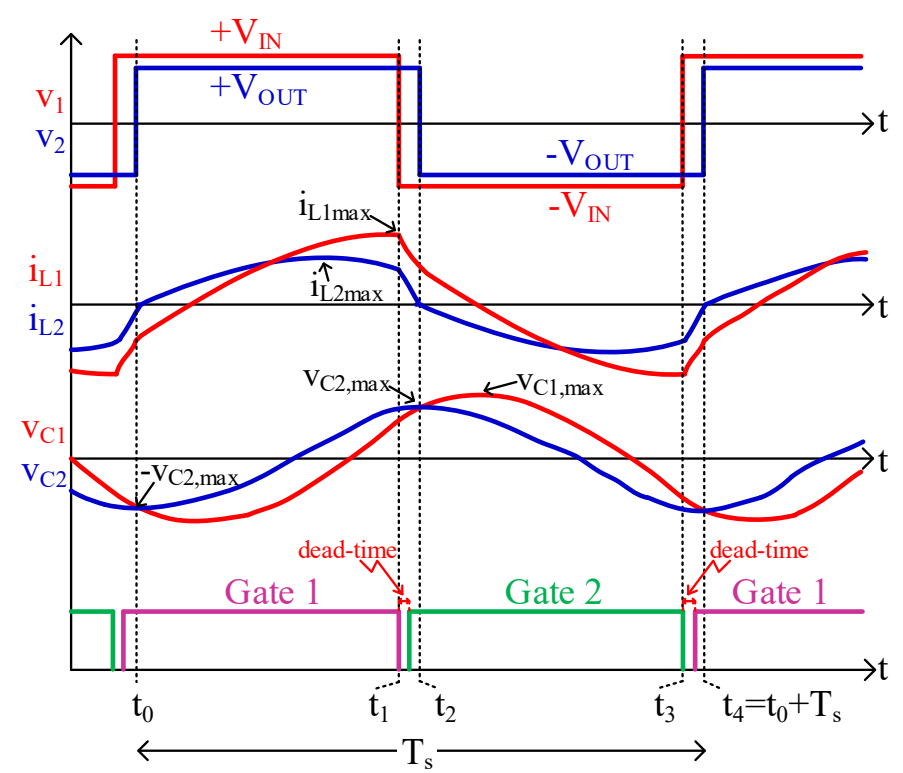

Fig. 2. Typical CLLC resonant converter operation for above resonant frequency in the forward power transfer mode.

In this paper, a detailed exact analysis approach based on state-plane analysis is proposed for the bidirectional fullbridge CLLC resonant converter. For this purpose, a new formulation of state-space equations is presented and the highorder system of CLLC resonant converter is decoupled into two lower-order systems. Based on the proposed method, the exact analysis of converter in CCM, the voltage and current stresses of the resonant elements and switching components, the gain ratio, soft switching criteria, and the boundary between $\mathrm{CCM} / \mathrm{DCM}$ are obtained. The accuracy and feasibility of the proposed method are verified by simulation and experiments and the results are compared with the FHA method.

\section{OPERATING MODES OF THE CLLC RESONANT CONVERTERS}

The circuit diagram of the bidirectional full-bridge CLLC resonant converter is shown in Fig. 1, where the voltage polarities and current directions for the forward power conversion are denoted in red and for the reverse power conversion are denoted in blue. Thanks to the symmetric structure of the CLLC resonant the circuit analysis of converter is the same for both cases. In this paper, only the forward power transfer mode will be discussed in details. The

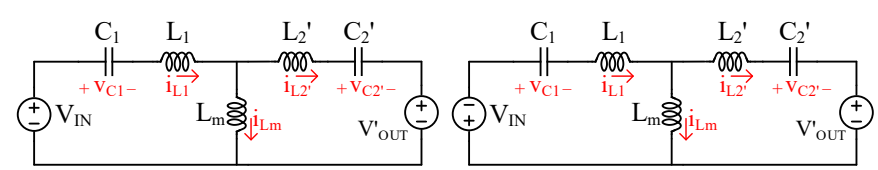

(a)

(b)

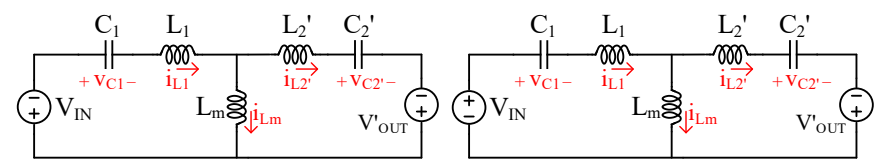

(c)

(d)

Fig. 3. Equivalent circuit of CLLC resonant converter in subinterval 1 (a), subinterval 2 (b), subinterval 3 (c), and subinterval 4 (d).

TABLE I

EXCHANGING THE NOTATIONS FOR THE FORWARD AND THE REVERSE POWER TRANSFER MODES

\begin{tabular}{ccc}
\hline Forward & & Reverse \\
\hline \hline $\mathrm{V}_{\mathrm{IN}}$ & $\leftrightarrow$ & $\mathrm{V}_{\text {OUT }}$ \\
$\mathrm{C}_{1}$ & $\leftrightarrow$ & $\mathrm{C}_{2}$ \\
$\mathrm{~L}_{1}$ & $\leftrightarrow$ & $\mathrm{L}_{2}$ \\
$\mathrm{~L}_{\mathrm{m}}$ & $\leftrightarrow$ & $\mathrm{L}_{\mathrm{m}}{ }^{\prime \prime}\left(=\mathrm{L}_{\mathrm{m}} / \mathrm{n}^{2}\right)$ \\
$\mathrm{L}_{2}^{\prime}\left(=\mathrm{n}^{2} \mathrm{~L}_{2}\right)$ & $\leftrightarrow$ & $\mathrm{L}_{1}{ }^{\prime}\left(=\mathrm{L}_{1} / \mathrm{n}^{2}\right)$ \\
$\mathrm{C}_{2}^{\prime}\left(=\mathrm{C}_{2} / \mathrm{n}^{2}\right)$ & $\leftrightarrow$ & $\mathrm{C}_{1}{ }^{\prime \prime}\left(=\mathrm{n}^{2} \mathrm{C}_{1}\right)$ \\
$\mathrm{V}_{\text {OUT }}\left(=\mathrm{nV}_{\text {OUT }}\right)$ & $\leftrightarrow$ & $\mathrm{V}_{\text {IN }}\left(=\mathrm{V}_{\text {IN }} / \mathrm{n}\right)$ \\
\hline
\end{tabular}

analysis of the converter in the reverse power transfer mode can be performed in the same manner just by exchanging the notations as shown in Table I. The primary active full bridge is composed of four GaN transistors. The switching network of the secondary side is also formed in a similar manner as the synchronous rectifier. The resonant tank is comprised of capacitors $C_{1}$ and $C_{2}$, the transformer magnetizing inductance $L_{m}$, and the primary and secondary leakage inductances $L_{l}$ and $L_{2}$. Depending on the desired power flow direction, the bridge of one side acts as inverter and that of the other side acts as synchronous rectifier.

Typical waveforms are shown in Fig. 2, assuming that the converter operates in the $\mathrm{CCM}$, and that secondary side $\mathrm{H}$ bridge acts as a diode rectifier, where the gate signals of transistors $\mathrm{S}_{5} \sim \mathrm{S}_{8}$ are applied at the $i_{L 2}^{\prime}$ zero crossing, i.e. $t_{2}$ and $t_{4}$. Depending on the switching state and the secondary side current, the CLLC resonant converter operates in four possible operation modes in a complete switching period. The equivalent circuits of each operation mode are shown in Fig. 3 . To have a single voltage level, the equivalent circuits are referred to their primary sides by defining:

$L_{2}{ }^{\prime}=n^{2} L_{2}, C_{2}{ }^{\prime}=C_{2} / n^{2}, V_{\text {OUT }}^{\prime}=n V_{\text {OUT }}, v_{2}{ }^{\prime}=n v_{2}$

There are four subintervals in a cycle during each one the converter operates in a particular mode:

Subinterval $1\left(t_{0} \leq t<t_{1}\right)$ : This interval begins with positivegoing zero crossing of the secondary current $i_{L 2}^{\prime}$. The primary current, $i_{L l}$, is negative and passes through $\mathrm{S}_{1}$ and $\mathrm{S}_{4}$ in the reverse mode operating of the GaNs which leads to $v_{I}=\mathrm{V}_{\mathrm{IN}}$. Also, $i_{L 2}^{\prime}$ is positive and the synchronous rectifying GaN transistors $\mathrm{S}_{5}$ and $\mathrm{S}_{8}$ are conducting causing $v_{2}^{\prime}=\mathrm{V}^{\prime}$ 'оuт. From 
the equivalent circuit shown in Fig 3(a), the state space equations of the CLLC resonant converter during subinterval 1 can be expressed as follow:

$$
\begin{aligned}
& \frac{d v_{C 1}(t)}{d t}=\frac{1}{C_{1}} i_{L 1}(t) \\
& \frac{d v_{C 2}^{\prime}(t)}{d t}=\frac{1}{C_{2}^{\prime}} i^{\prime}{ }_{L 2}^{\prime}(t) \\
& \frac{d i_{L 1}(t)}{d t}=-\frac{L_{2}^{\prime}+L_{m}}{\Gamma} v_{C 1}-\frac{L_{m}}{\Gamma} v_{C 2}^{\prime}-\frac{L_{2}^{\prime}+L_{m}}{\Gamma} v_{1}-\frac{L_{m}}{\Gamma} v_{2}{ }_{2} \\
& \frac{d i_{L 2}^{\prime}(t)}{d t}=-\frac{L_{m}}{\Gamma} v_{C 1}-\frac{L_{1}+L_{m}}{\Gamma} v_{C 2}^{\prime}-\frac{L_{m}}{\Gamma} v_{1}-\frac{L_{1}+L_{m}}{\Gamma} v_{2}
\end{aligned}
$$

where $\Gamma$ is defined as:

$\Gamma=L_{1} L_{2}{ }_{2}+L_{1} L_{m}+L_{2}{ }_{2} L_{m}$

This interval ends when the gate signal "Gate 1" to the transistors $\mathrm{S}_{1}$ and $\mathrm{S}_{4}$ is turned OFF.

Subinterval $2\left(t_{1} \leq t<t_{2}\right)$ : Fig. 3 (b) shows the circuit in this subinterval. At the beginning, the gate signals force all the inverter side transistors to be OFF. The transistors $S_{2}$ and $S_{3}$ are turned $\mathrm{ON}$ during this subinterval with zero voltage switching (ZVS), and conduct in the reverse mode, hence $v_{l}=$ $-V_{\text {IN }}$. This subinterval ends when $i_{L 2}^{\prime}$ reaches zero. Consequently, the zero current switching (ZCS) is obtained for rectifying GaN transistors $\mathrm{S}_{6}$ and $\mathrm{S}_{7}$. The state space equations of this subinterval are similar to (2) knowing that $v_{l}$ has the opposite polarity from subinterval 1 .

Subinterval $3\left(t_{2} \leq t<t_{3}\right)$ : As shown in Fig. 3(c), in this subinterval, the switches $S_{2}$ and $S_{3}$ are $O N$ and the input voltage with reverse polarity is applied to the circuit, so $v_{l}=-$ $\mathrm{V}_{\mathrm{IN}}$. The secondary side current is negative and $\mathrm{GaN}$ rectifiers $\mathrm{S}_{6}$ and $\mathrm{S}_{7}$ are $\mathrm{ON}$, hence $v_{2}^{\prime}=-\mathrm{V}^{\prime}$ out. This interval is similar to subinterval 1 except that the polarity of the input and output voltages are reversed. Therefore, a similar analysis can be performed. This interval ends when the gate signal "Gate 2" to the transistors $S_{2}$ and $S_{3}$ is turned OFF.

Subinterval $4\left(\mathrm{t}_{3} \leq \mathrm{t}<\mathrm{t}_{4}\right)$ : The circuit diagram during this interval is illustrated in Fig. 3(d). In this interval, the transistors $\mathrm{S}_{1}$ and $\mathrm{S}_{4}$ are turned ON under ZVS conditions due to the negative current of the tank at the beginning of this interval. This interval ends when $i_{L 2}^{\prime}$ reaches zero which provides the ZCS condition for transistors $\mathrm{S}_{5}$ and $\mathrm{S}_{8}$. The state space equations of this subinterval are similar to (2) with $v_{l}=$ $\mathrm{V}_{\mathrm{IN}}$ and $v_{2}^{\prime}=-\mathrm{V}_{\text {OUT }}$.

The four sets of state-space equations are coupled and the state-plane trajectory cannot be represented in two or three dimensional coordinates. Therefore, a new method is given here for the state-plane analysis of the CLLC resonant converter.

\section{Proposed New State-Plane Analysis of the ClLC RESONANT CONVERTER}

This section provides new decoupled sets of state-space equations for analysis of the CLLC resonant converter. Let us

\begin{tabular}{|c|c|c|}
\hline Definition [unit] & Parameter & Value \\
\hline Base voltage for P-type [V] & $V_{\text {base }, P}$ & $V_{I N}$ \\
\hline Base Voltage for N-type [V] & $V_{\text {base }, N}$ & $V_{I N}$ \\
\hline Base impedance for P-type [ $\Omega]$ & $R_{0, P}$ & $\sqrt{L_{P} / C_{P}}$ \\
\hline Base impedance for $N$-type $[\Omega]$ & $R_{0, N}$ & $\sqrt{L_{N} / C_{N}}$ \\
\hline Base current for P-type [A] & $I_{\text {base }, P}$ & $V_{I N} / R_{0, P}$ \\
\hline Base current for N-type [A] & $I_{\text {base }, N}$ & $V_{I N} / R_{0, N}$ \\
\hline Base frequency $[\mathrm{Hz}]$ & $f_{0}$ & $\frac{1}{2 \pi \sqrt{L_{1} C_{1}}}$ \\
\hline
\end{tabular}
define the new state space variables $i_{L P}, i_{L N}, v_{C P}$, and $v_{C N}$ as (4).
TABLE II

BASE VALUES FOR THE PARAMETERS OF SRC-P AND SRC-N

$i_{L P}=a_{P} i_{L 1}+i_{L 2}^{\prime}$

$i_{L N}=a_{N} i_{L 1}-i_{L 2}^{\prime}$

$v_{C P}=e_{P} v_{C 1}+v_{C 2}^{\prime}$

$v_{C N}=e_{N} v_{C 1}-v_{C 2}^{\prime}$

where $a_{P}, a_{N}, e_{P}$, and $e_{N}$ are constants that depend on circuit parameters as described in the Appendix:

$a_{P}=K e_{P}$

$a_{N}=K e_{N}$

$e_{P}=\frac{K L_{2}^{\prime}-L_{1}+(K-1) L_{m}+\sqrt{\left(L_{1}-K L_{2}^{\prime}+L m-K L m\right)^{2}+4 K L m^{2}}}{2 K L m}$

$e_{N}=\frac{-K L_{2}^{\prime}+L_{1}+(1-K) L_{m}+\sqrt{\left(L_{1}-K L_{2}^{\prime}+L m-K L m\right)^{2}+4 K L m^{2}}}{2 K L m}$

In which $K=C_{2} / C_{1}$ represents the ratio of resonant capacitors. By substituting (4) into (2), the new decoupled state space equations denoted by $\mathrm{P}$ and $\mathrm{N}$ are obtained.

$$
\begin{aligned}
& \left\{\begin{array}{l}
\frac{d v_{C P}}{d t}=\frac{1}{C_{P}} i_{L P} \\
\frac{d i_{L P}}{d t}=-\frac{1}{L_{P}} v_{C P}-\frac{a_{P} L_{2}^{\prime}+\left(1+a_{P}\right) L m}{\Gamma} v_{1}-\frac{L_{1}+\left(1+a_{P}\right) L m}{\Gamma} v^{\prime}{ }_{2}
\end{array}\right. \\
& \left\{\begin{array}{l}
\frac{d v_{C N}}{d t}=\frac{1}{C_{N}} i_{L N} \\
\frac{d i_{L N}}{d t}=-\frac{1}{L_{N}} v_{C N}-\frac{a_{N} L_{2}+\left(1-a_{N}\right) L m}{\Gamma} v_{1}+\frac{L_{1}+\left(1-a_{N}\right) L m}{\Gamma} v_{2}{ }_{2}
\end{array}\right.
\end{aligned}
$$

where $C_{P}=C_{N}=C_{2}^{\prime}$, and $L_{P}$ and $L_{N}$ are the equivalent inductances for $\mathrm{P}$ and $\mathrm{N}$ states:

$$
\begin{aligned}
L_{P} & =\frac{\left(e_{P}+e_{N}\right)\left(L_{1} L_{2}{ }_{2}+L_{1} L_{m}+L_{2}{ }_{2} L_{m}\right)}{K\left(L^{\prime}{ }_{2}+L_{m}\right) e_{P}+\left(L_{1}+2 L_{m}\right) e_{N}+L_{m}} \\
L_{N} & =\frac{\left(e_{P}+e_{N}\right)\left(L_{1} L_{2}^{\prime}+L_{1} L_{m}+L_{2}{ }_{2} L_{m}\right)}{\left(L_{1}+L_{m}\right) e_{P}+K\left(L_{2}{ }_{2}+L_{m}\right) e_{N}-L_{m}\left(K e_{N} e_{P}+1\right) e_{N}}
\end{aligned}
$$

To generalize the analysis, the quantities are presented in normalized form using the base quantities defined in Table II.

The normalized state space equations of CLLC resonant converter can be expressed as follow: 


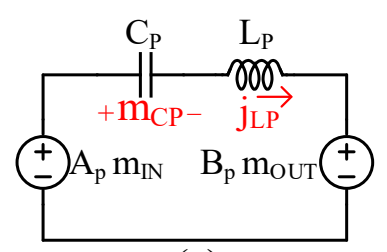

(a)

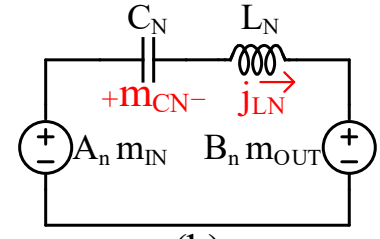

(b)
Fig. 4. Equivalent circuit for SRC-P (a) and SRC-N (b).

$$
\begin{aligned}
& \left\{\begin{aligned}
\frac{d m_{C P}}{d t}= & \frac{1}{\sqrt{L_{P} C_{P}}} j_{L P} \\
\frac{d j_{L P}}{d t}=- & -\frac{R_{0, P}}{L_{P}} m_{C P}-\frac{a_{P} L^{\prime}{ }_{2}+\left(1+a_{P}\right) L m}{\Gamma} R_{0, P} \\
& -\frac{L_{1}+\left(1+a_{P}\right) L m}{\Gamma} R_{0, P} M
\end{aligned}\right. \\
& \left\{\begin{aligned}
\frac{d m_{C N}}{d t}= & \frac{1}{\sqrt{L_{N} C_{N}}} j_{L N} \\
\frac{d j_{L N}}{d t}=- & \frac{R_{0, N}}{L_{N}} m_{C N}-\frac{a_{N} L_{2}{ }_{2}+\left(1-a_{N}\right) L m}{\Gamma} R_{0, N} \\
& +\frac{L_{1}+\left(1-a_{N}\right) L m}{\Gamma} R_{0, N} M
\end{aligned}\right.
\end{aligned}
$$

where $m$ and $j$ denote the normalized voltage and current, respectively.

Fig. 4(a) and 4(b) represent the equivalent circuits described by (10) and (11) [30] which are denoted by the P-type series resonant converter (SRC-P) and the $\mathrm{N}$-type series resonant converter (SRC-N), respectively. One can see that the behavior of CLLC resonant converter can be modeled by two series resonant converters which shown in Fig. 4. Polarity of $m_{I N}$ and $m_{O U T}$ depend to the particular subinterval. The parameters $A_{P}, B_{P}, A_{N}$, and $B_{N}$ are defined as follow:

$A_{P}=\left(a_{P}\left(L^{\prime}{ }_{2}+L_{m}\right)+L m\right) \times L_{P} / \Gamma$

$B_{P}=\left(L_{m}\left(a_{P}+1\right)+L_{1}\right) \times L_{P} / \Gamma$

$A_{N}=\left(a_{N}\left(L^{\prime}{ }_{2}+L_{m}\right)-L m\right) \times L_{N} / \Gamma$

$B_{N}=\left(L_{m}\left(a_{N}-1\right)-L_{1}\right) \times L_{N} / \Gamma$

The state-plane diagram of each series resonant converter consists of four circular arcs [17]. Fig. 5 shows the state-plane diagram of the SRC-P and SRC-N, where the center and radius of arcs are given in Table III. The included angles of the arcs can be found by solving the geometry of the stateplane as shown in Table IV.

From Fig. 5, It can be observed that for the half switching period, the sum of the arc angles of subintervals 1 and 2, i.e., $\alpha_{x}+\beta_{x}$, satisfies the following condition for $\mathrm{x} \in\{\mathrm{P}, \mathrm{N}\}$.

$\alpha_{x}+\beta_{x}=\frac{\omega_{0, x}}{2 f_{s w}}=\frac{\pi}{F_{x}} \quad, F_{x}=\frac{f_{s w}}{f_{0}}$

where $\omega_{0, x}$ is the base value of angular frequency and $F_{x}$ is the normalized switching frequency with $\mathrm{x} \in\{\mathrm{P}, \mathrm{N}\}$.
TABLE III

RADIUS (R) AND CENTER (O) OF THE SRC-P AND SRC-N ARCS

\begin{tabular}{c|cc}
\hline \hline & SRC-P & SRC-N \\
\hline $\mathrm{r}_{1}$ & $\sqrt{\left(-M_{C P 0}+A_{P}+B_{P} M\right)^{2}+J_{L P 0}^{2}}$ & $\sqrt{\left(M_{C N 0}+A_{N}-B_{N} M\right)^{2}+J_{L N 0}^{2}}$ \\
$\mathrm{r}_{2}$ & $\sqrt{\left(M_{C P 0}+A_{P}-B_{P} M\right)^{2}+J_{L P 0}^{2}}$ & $\sqrt{\left(-M_{C N}+A_{N}+B_{N} M\right)^{2}+J_{L N 0}^{2}}$ \\
$\mathrm{O}_{1}$ & $A_{P}+B_{P} \times M$ & $A_{N}+B_{N} \times M$ \\
$\mathrm{O}_{2}$ & $A_{P}-B_{P} \times M$ & $A_{N}-B_{N} \times M$ \\
$\mathrm{O}_{3}$ & $-A_{P}-B_{P} \times M$ & $-A_{N}-B_{N} \times M$ \\
$\mathrm{O}_{4}$ & $-A_{P}+B_{P} \times M$ & $-A_{N}+B_{N} \times M$ \\
\hline \hline
\end{tabular}

TABLE IV

SOME ANGELES For the STATE-PLANE DIAGRAMS OF SRC-P AND SRC-N

\begin{tabular}{ccc}
\hline \hline Angle & Value & Condition \\
\hline$\alpha_{P}$ & $\cos ^{-1}\left(\frac{r_{2}^{2}-r_{1}^{2}+4 a^{2}}{4 a \times r_{2}}\right) \mp$ & $-\rightarrow P$ \\
$\alpha_{N}$ & $\cos ^{-1}\left(\frac{r_{1}^{2}-r_{2}^{2}+4 a^{2}}{4 a \times r_{1}}\right) \pm \lambda$ & $+\rightarrow P$ \\
\hline$\beta_{P}$ & & $-\rightarrow N$ \\
$\beta_{N}$ & $\sin ^{-1}\left(\frac{r_{2}}{r_{1}} \sqrt{1-\left(\frac{r_{1}^{2}-r_{2}^{2}-4 b^{2} M^{2}}{4 b \times M \times r_{2}}\right)^{2}}\right)$ & same \\
\hline$\delta_{P}$ & $\cos ^{-1}\left(\frac{r_{1}^{2}-r_{2}^{2}-4 b^{2} M^{2}}{ \pm 4 b \times M \times r_{2}}\right)$ & $+\rightarrow P$ \\
$\delta_{N}$ & \\
\hline$\lambda_{P}$ & & $-\rightarrow N$ \\
$\lambda_{N}$ &
\end{tabular}

In the following section, component stresses are analyzed using the state-plane diagram.

\section{A. Stresses of Components}

Calculations of voltage and current stresses of the resonant elements and switches are an important step in designing resonant converters. Selection of switches and other components is commonly considered based on their maximum voltage and current.

1) Current stresses

Fig. 6 shows three possible trajectories depending on the value of $\beta_{P}$ which it is the arc angle of subinterval $1 . \theta_{0}$ is the angle corresponding to the time difference between the zero crossing of $i_{L 1}$ and $i_{L 2}$.

For $\beta_{\mathrm{P}}<\pi / 2$, the peak current values, $J_{L P} P$ and $J_{L P} N$, can be calculated from Fig 6 (a) as:

$J_{L P} P=r_{1 P} \sin \left(\alpha_{P}+\delta_{P}\right)$

$J_{L P} N=r_{1 N} \sin \left(\alpha_{N}-\delta_{N}\right)$

The radii $r_{2, P}$ and $r_{2, N}$ of the state-plane trajectory in Fig. 6 (a), can be found as follow:

$$
\begin{aligned}
& r_{2, P}^{2}=r_{1, P}^{2}+\left(2 A_{P}\right)^{2}-2 r_{1, P}\left(2 A_{P}\right) \cos \left(\alpha_{P}+\delta_{P}\right) \\
& r_{2, N}^{2}=r_{1, N}^{2}+\left(2 A_{N}\right)^{2}-2 r_{1, N}\left(2 A_{N}\right) \cos \left(\alpha_{N}-\delta_{N}\right)
\end{aligned}
$$

From (16) and (17), and using the trigonometric equation of $\sin x=\sqrt{1-\cos ^{2} x}$, the following equations are obtained: 


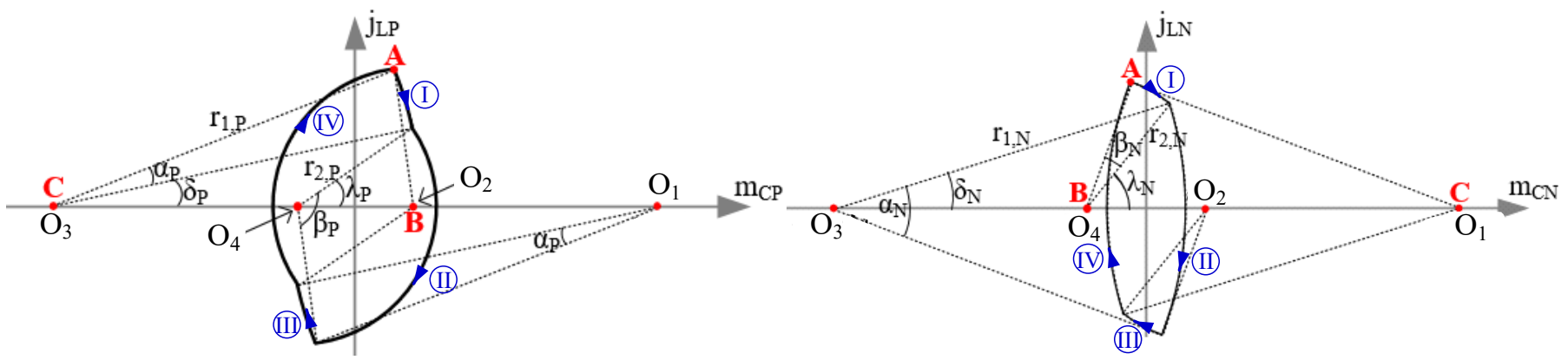

Fig. 5. State-plane diagram of the CLLC resonant converter operating on CCM, for SRC-P (left) and SRC-N (right).

$\sin \left(\alpha_{P}+\delta_{P}\right)=\sqrt{1-\left(\frac{r_{2, P}^{2}-r_{1, P}^{2}-4 A_{P}^{2}}{4 A_{P} r_{1, P}}\right)^{2}}$

$\sin \left(\alpha_{N}-\delta_{N}\right)=\sqrt{1-\left(\frac{r_{1, N}^{2}-r_{2, N}^{2}+4 A_{N}^{2}}{4 A_{N} r_{1, N}}\right)^{2}}$

By substituting (18) and (19) into (14) and (15), the peak current values can be found as:

$J_{L P} P=r_{1 P} \sqrt{1-\left(\frac{r_{2, P}^{2}-r_{1, P}^{2}+4 A_{P}^{2}}{4 A_{P} r_{1, P}}\right)^{2}}$

$J_{L P} N=r_{1 N} \sqrt{1-\left(\frac{r_{1, N}^{2}-r_{2, N}^{2}+4 A_{N}^{2}}{4 A_{N} r_{1, N}}\right)^{2}}$

Using (20) and (21), the peak current of the primary and secondary inductors, $I_{L I, \max }$ and $I_{L 2, \max }$, can be expressed as:

$I_{L 1, \max }=\frac{1}{a_{P}+a_{N}}\left(J_{L P} P \times I_{\text {base }, P}+J_{L P} N \times I_{\text {base }, N}\right)$

$I_{L 2, \max }=\frac{n}{a_{P}+a_{N}}\left(a_{P} J_{L P} P \times I_{\text {base }, P}-a_{N} J_{L P} N \times I_{\text {base }, N}\right)$

For $\beta_{\mathrm{P}}>\pi / 2+\theta_{0}$, as shown in Fig. 6(c) the peak values $J_{L P} P$ and $J_{L P} N$ can be obtained as:

$J_{L P} P i_{L 1}=r_{1 P} \cos \left(\lambda_{P}-\theta_{0}\right)$

$J_{L P} N_{-} i_{L 1}=r_{1 N} \sin \left(\left(\theta_{0}+\frac{\pi}{2}\right) \frac{I_{\text {base }, N}}{I_{\text {base }, P}}-\delta_{N}\right)$

$J_{L P} P_{-} i_{L 2}=r_{1 P} \cos \left(\lambda_{P}\right)$

$J_{L P} N_{-} i_{L 2}=r_{1 N} \sin \left(\frac{\pi}{2} \frac{I_{\text {base }, N}}{I_{\text {base }, P}}-\delta_{N}\right)$

On the other hand for $\pi / 2<\beta_{\mathrm{P}}<\pi / 2+\theta_{0}$, the maximum value of the primary side current happens at the switching instant. So, $J_{L P} P$ and $J_{L P} N$ should be calculated from (20) and (21) in order to find $i_{L I, \max }$. The peak value of secondary current, happens at $\omega_{0} \mathrm{t}=\pi / 2$. Therefore, $J_{L P} P$ and $J_{L P} N$ should be calculated from (26) and (27) in order to find $i_{L 2, \max }$.

2) Voltage stresses

In steady state, the peak tank capacitor voltages occur when the inductor currents reach zero since the resonant capacitor
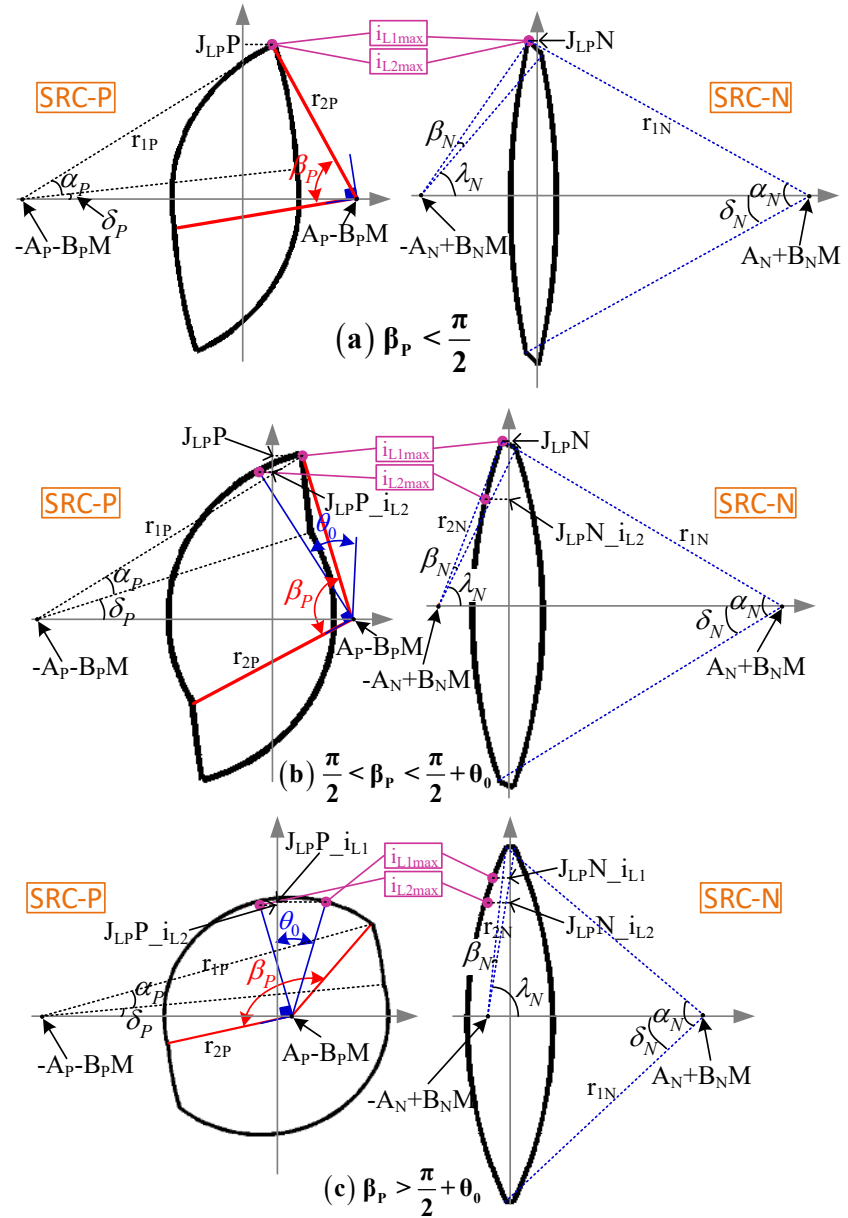

Fig. 6. Maximum currents of the primary and the secondary sides in SRC-P and SRC-N state-plane diagrams for; $\beta_{\mathrm{p}}<\pi / 2$ (a), $\pi / 2<\beta_{\mathrm{p}}<\pi / 2+\theta_{0}$ (b), and $\beta_{\mathrm{P}}>\pi / 2+\theta_{0}$ (c).

and inductor are in series on both sides, hence the capacitor voltage is maximum when the inductor current is zero. In this condition one can found from (4) that:

$i_{L P}=a_{P} i_{L 1}+i_{L 2}^{\prime}=i_{L 2}^{\prime}$

$i_{L N}=a_{N} i_{L 1}-i_{L 2}^{\prime}=-i_{L 2}^{\prime}$

which means $i_{L P}=-i_{L N}$ or in the normalized form:

$j_{L P}=-\frac{I_{\text {base }, N}}{I_{\text {base }, P}} j_{L N}$

which is a line in the $j_{L P-j} j_{L N}$ coordinate system. Therefore, we need to plot a new state-plane trajectory, i.e. $j_{L P-j} j_{L N}$. Fig. 7 


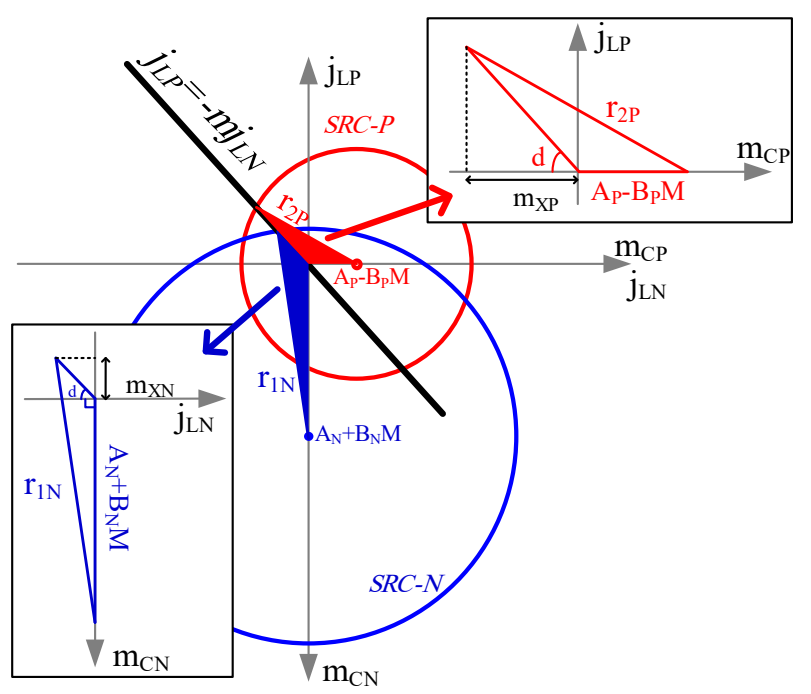

Fig. 7. The $j_{L P-} j_{L N}$ state-plane trajectory for calculating $\mathrm{v}_{\mathrm{Clmax}}$.

shows the state-plane trajectory of $j_{L P-j_{L N}}$ which is obtained by superimposing loci of $j_{L P}-m_{C P}$ and $j_{L N}-m_{C N}$. The related triangles for the calculation of normalized voltage at $i_{L I}=0$, $m_{X P}$ and $m_{X N}$, are redrawn in Fig. 7.

Using the law of cosines in Fig. 7, one can write:

$r_{2 P}^{2}=\left(A_{P}-B_{P} M\right)^{2}+\frac{m_{X P}^{2}}{\cos ^{2} d}-2\left(A_{P}-B_{P} M\right) \frac{m_{X P}}{\cos d} \cos (\pi-d)$

$r_{1 N}^{2}=\left(A_{N}+B_{N} M\right)^{2}+\frac{m_{X N}^{2}}{\sin ^{2} d}-2\left(A_{N}+B_{N} M\right) \frac{m_{X N}}{\sin d} \sin \left(\frac{\pi}{2}+d\right)$

where $d=\tan ^{-1}\left(I_{\text {base }, N} / I_{\text {base }, P}\right)$. Therefore, $m_{X P}$ and $m_{X N}$ are calculated as:

$m_{X P}=-\left(A_{P}-B_{P} M\right) \cos ^{2} d+\cos d \sqrt{r_{2 P}^{2}-\sin ^{2} d\left(A_{P}-B_{P} M\right)^{2}}$

$m_{X N}=-\left(A_{N}+B_{N} M\right) \sin ^{2} d+\sin d \sqrt{r_{1 N}^{2}-\cos ^{2} d\left(A_{N}+B_{N} M\right)^{2}}$

Consequently, the maximum voltage across $C_{l}, v_{C l \max }$, can be calculated by transforming normalized variables from $\mathrm{P}$ and $\mathrm{N}$ states to the real value.

$V_{C 1, \max }=\frac{1}{e_{P}+e_{N}}\left(m_{X P} \times V_{\text {base }, P}+m_{X N} \times V_{\text {base }, N}\right)$

On the other hand, the maximum voltage across $C_{2}, v_{C 2 \max }$, occurs when $i_{L 2}$ reaches zero. So, the normalized voltage can be expressed as:

$m_{C P} P=r_{2 P} \cos \left(\lambda_{P}\right)-A_{P}+B_{P} M$

$m_{C P} N=r_{2 N} \cos \left(\lambda_{N}\right)-A_{N}-B_{N} M$

where $m_{C P} P$ and $m_{C P} N$ are the normalized voltages when $i_{L 2}=0$, in the SRC-P and SRC-N, respectively.

Knowing $m_{C P} P$ and $m_{C P} N, V_{C 2, \max }$ can be obtained as:

$V_{C 2, \max }=\frac{1 / n}{e_{P}+e_{N}}\left(e_{P} M_{C P} P \times V_{\text {base }, P}-e_{N} M_{C P} N \times V_{\text {base }, N}\right)$

\section{B. Soft Switching Conditions}

One of the most important features of resonant converters is the zero voltage switching capability of the devices. For

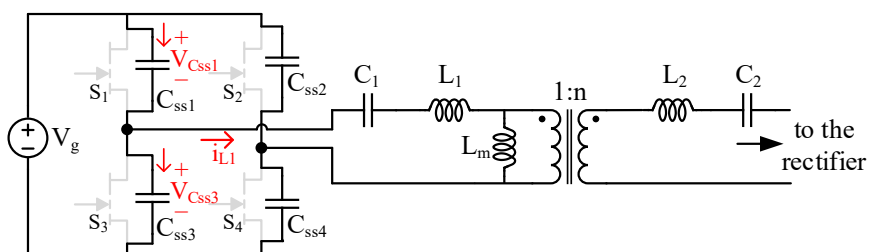

Fig. 8. Circuit condition between subinterval 1 and 2 for the ZVS analysis.

CLLC resonant converter, in most literature first harmonic approximation is used to find the soft switching conditions. In this paper, the accurate state-plane analysis is used to examine exact soft switching conditions.

As shown in Fig. 2 at the end of subinterval $1, S_{1}$ and $S_{4}$ conduct, $i_{L I}$ is positive and the voltage across drain-source capacitors $C_{S S I}$ and $C_{S S 3}$ are 0 and $+\mathrm{V}_{\mathrm{IN}}$, respectively. During the dead time as shown in Fig. 8, all inverter switches are OFF and the primary side inductor current flows through the transistor parasitic output capacitances. Therefore:

$V_{C S S 1}+V_{C S S 3}=V_{I N}$

As the switches are similar from the capacitor current formula $i=C(d v / d t)$ one can find that:

$I_{C S S 1}+I_{C S S 3}=0 \rightarrow i_{L 1}=\frac{I_{C S S 1}}{2}=-\frac{I_{C S S 3}}{2}$

Eq. (39) implies that the total energy of the two parasitic capacitors remains unchanged during this subinterval, as a result, no power is transferred to the resonant network.

This mode will continue until the voltage across $C_{s s 3}$ is discharged to zero. After that, the GaN transistors $S_{2}$ and $S_{3}$ conduct in the reverse direction, therefore ZVS can be achieved. By assuming linear discharging, the minimum dead time to ensure ZVS is given by:

$\frac{I_{t=t_{t t}}}{2}=C_{S S} \frac{d V_{C S S}}{d t} \cong C_{S S} \frac{V_{I N}-0}{t_{d t}} \Rightarrow t_{d t}=\frac{2 C_{S S} V_{I N}}{I_{t=t_{d t}}}$

In steady state, the state-plane trajectory is symmetrical. Hence [26];

$I_{L 1}(0)=-I_{L 1}\left(\pi / \omega_{s}\right)$

By substituting (41) into (40), the minimum dead-time which ensures ZVS can be calculated as:

$t_{d t} \geq \frac{2 C_{S S} V_{I N}}{I_{t}}$

Obviously, the dead-time depends on the input voltage, the drain-source capacitance of inverter switches, and the initial value of primary current which is a function of circuit parameters and the load. The procedure to drive the initial value of resonant elements has been discussed in [26].

On the other hand, the maximum allowable dead time for remaining in ZVS is $\alpha+\theta_{0}$ when the $i_{L 1}$ reaches zero. Therefore, the dead-time must be selected as (43) to meet operating at the ZVS condition.

$\frac{2 C_{S S} V_{I N}}{I_{t=0}} \leq t_{d t} \leq \alpha+\theta_{0}$

It should be mentioned that this ZVS condition is a general formula and is also valid when other parasitic capacitances 


\section{IEEE POWER ELECTRONICS REGULAR PAPER/LETTER/CORRESPONDENCE}

such transformer inter-winding and PCB interlayer capacitances exist. In this case the value of $I_{t=0}$ with consideration of parasitic capacitances should be calculated and used. Fig. 9 represents the ZVS operating region as a function of voltage gain and dead-time equivalent angle.

\section{Output Characteristic}

The output characteristics describe how the converter output voltage depends on the load current. As can be seen in Fig. 2 during the half switching period where the secondary side current $i_{L 2}$ is positive, the secondary resonant capacitor voltage increases from its negative peak $-V_{C 2, \max }$ to its positive peak $+V_{C 2, \max }$. This voltage change corresponds to the net charge transferred to the load, hence:

$I_{\text {Load }}=<i_{L 2}>=\frac{2}{T_{s}} \int_{0}^{\frac{T_{s}}{2}} i_{C 2} d t=\frac{2}{T_{s}}\left(C_{2} \Delta V_{C 2}\right)=\frac{4 C_{2} V_{C 2, \max }}{T_{S}}$

By substituting (37) into (44) and normalizing the equation, we can find the relationship between normalized current $J$, and the voltage stresses of SRC-P and SRC-N:

$\mathrm{J}=\frac{4 C_{2} F_{S}}{e_{P}+e_{N}}\left(e_{P} m_{C P, P}-e_{N} m_{C P, N}\right)$

Now, substituting (35) and (36) into (45), the relationship between normalized output voltage $M$, normalized load current $J$, and normalized switching frequency which features the output characteristics can be expressed as:

$$
\begin{aligned}
\mathrm{J}=\frac{4 C_{2} F_{S}}{e_{P}+e_{N}}\{ & e_{P}\left(r_{2 P} \cos \left(\lambda_{P}\right)+A_{P}-B_{P} M\right)- \\
& \left.-e_{N}\left(r_{2 N} \cos \left(\lambda_{N}\right)-A_{N}-B_{N} M\right)\right\}
\end{aligned}
$$

Fig. 10 shows the output characteristics of the CLLC resonant converter for different normalized switching frequencies.

The output short circuit current, $J_{S C}$, can be calculated using the output characteristics by substituting $M=0$ into (46).

$J_{S C}=\frac{4 C_{2} F_{S}}{e_{P}+e_{N}}\left(e_{P}\left(r_{2 P} \cos \left(\lambda_{P}\right)+A_{P}\right)-e_{N}\left(r_{2 N} \cos \left(\lambda_{N}\right)-A_{N}\right)\right)$

It can be seen that the converter's short-circuit current is inherently limited.

\section{Control Plane Characteristics}

One of the most informative curves for analysis and design of resonant converters is the steady control plane characteristics i.e. voltage conversion ratio, $M$, vs. normalized switching frequency, $F$. The load characteristics can be superimposed on the converter output characteristics to determine the output voltage vs. switching frequency. For a resistive load satisfying $I=V / R$ or in the normalized form:

$J=M Q$

with $Q=\sqrt{L_{1} / C_{1}} / R, J$ can be eliminated from (46) by substituting (48) into it.

$$
\mathrm{M}=\frac{4 C_{2} f_{0} F}{\left(e_{P}+e_{N}\right) \mathrm{Q}}\left(e_{P} M_{C P, P}-e_{N} M_{C P, N}\right)
$$

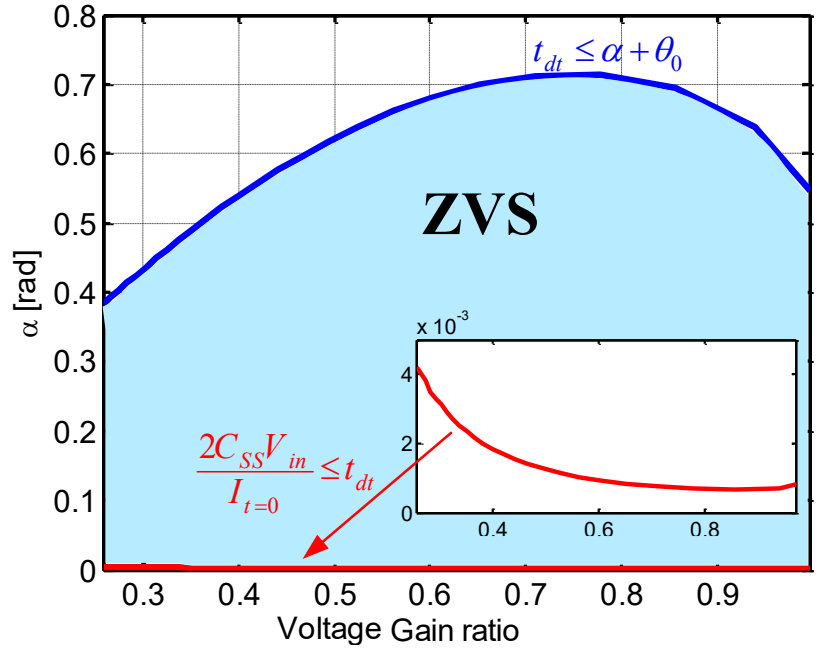

Fig. 9. The ZVS operating region as a function of voltage gain and dead-time equivalent angle.

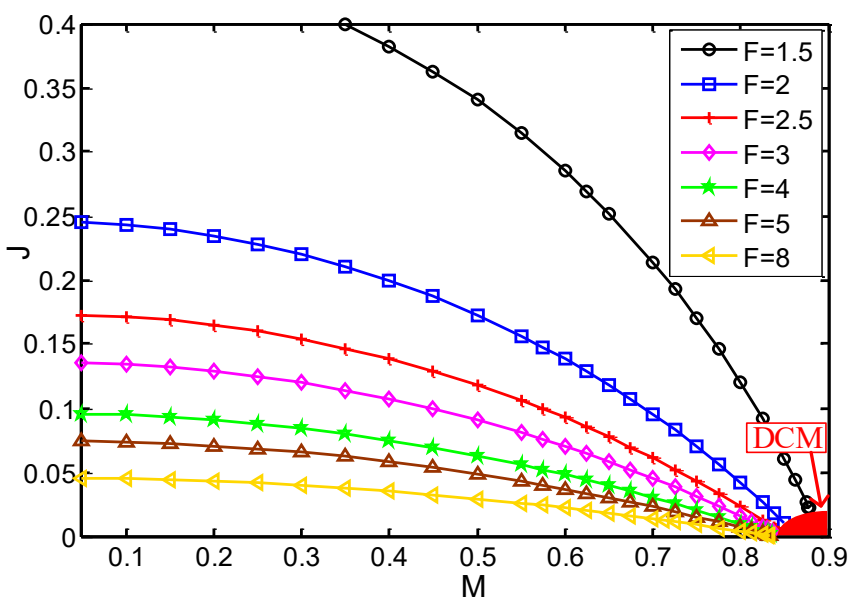

Fig. 10. Output characteristics of the CLLC resonant converter for different normalized switching frequencies.

Eq. (49) reveals the relationship between $M$ and $F$ which can be used in the control of CLLC resonant converter.

\section{E. Boundary Condition between CCM and DCM}

Right before subinterval 1, when $i_{L 2}$ reaches zero if the voltage $V_{2}$ in Fig. 1 is lower than $V_{O U T}$, the four bridge rectifier transistors cannot conduct and $i_{L 2}$ remains at zero. Therefore,

$i_{L 2}=0 \rightarrow i_{L 1}=i_{L m} \rightarrow \frac{d i_{L 1}}{d t}=\frac{d i_{L m}}{d t} \rightarrow v_{L 1}=\frac{L_{1}}{L_{m}} v_{L m}$

Writing Kirchhoff's Voltage Law in Fig. 11:

$-V_{1}+v_{C 1}+v_{L 1}+v_{L m}=0$

$-v_{L m}+v_{L 2}^{\prime}+v_{C 2}^{\prime}+V_{2}^{\prime}=0$

By solving (51) and (52), and knowing that $v_{L 2}$ is equal zero, $v_{C 2}$ is maximum and $V_{1}=V_{I N}$, then $V_{2}^{\prime}$ becomes:

$V_{2}^{\prime}=\frac{L_{m}}{L_{1}+L_{m}} V_{I N}+\frac{L_{m}}{L_{1}+L_{m}} v_{C 1}+v_{C 2, \max }^{\prime}$

where $v_{C l}$ at this instant can be obtained from (4) and (35): 


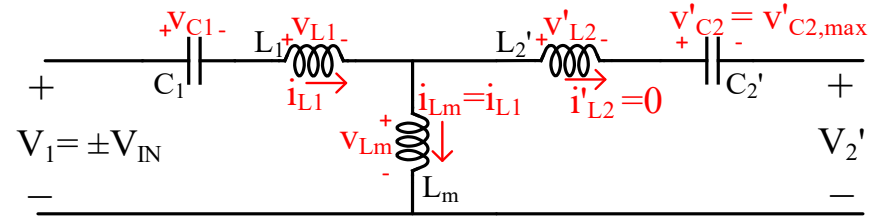

Fig. 11. The circuit diagram of the resonant tank for the DCM condition.

$v_{C 1}=\frac{v_{C P}-v_{C 2}}{e_{P}}=\frac{\left(r_{2 P}+A_{P}-B_{P} M\right) V_{I N}-v_{C 2, \max }^{\prime}}{e_{P}}$

By substituting (54) into (53), $V_{2}^{\prime}$ would then become:

$V_{2}^{\prime}=\frac{L_{m}}{L_{1}+L_{m}} \frac{e_{P}+r_{2 P}+A_{P}-B_{P} M}{e_{P}} V_{I N}+\frac{e_{P}-1}{e_{P}} v_{C 2, \max }$

where $v_{C 2, \max }$ was defined in (37).

The constraint for CCM operation $\left(V_{\text {rectifier }}>\mathrm{V}_{\text {OUT }}\right)$ in normalized form can be described by:

$M<\frac{\left(e_{P}+r_{2 P}+A_{P}\right) L_{m}+\left(e_{P}-1\right)\left(L_{1}+L_{m}\right) \times v_{C 2, \max } / V_{I N}}{e_{P}\left(L_{1}+L_{m}\right)+B_{P} L_{m}}$

Fig. 12 shows the control plane characteristics of the CLLC resonant converter and the DCM boundary. This map is useful for design purpose as the designer can overlay the operating region on it and see how the gain is changed with frequency and load and can find out if the converter operates in DCM.

When the switching frequency equals to the resonant frequency $(\mathrm{F}=1)$ then $\beta_{P}=\pi$. It means the switching-period consists of subintervals 1 and 3 and the duration of subintervals 2 and 4 is zero $\left(\alpha_{P}=0\right)$. The state-plane diagrams of SRC-P and SRC-N are given by two semicircles, as shown in Fig. 13.

In this condition equations (22) through (27) will be used to obtain $i_{L 1, \max }$, and $i_{L 2, \max }$. The peak capacitor voltages $v_{C 1, \max }$ and $v_{C 2, \max }$, can be calculated from (34) and (37).

\section{EXPERIMENTAL VERIFICATION}

A $3 \mathrm{~kW}$ bidirectional CLLC resonant converter with the specifications as listed in Table $\mathrm{V}$ has been developed to validate the proposed analysis. The prototype is built using GS66508B GaN transistors on both sides. As the synchronous rectification is not a primary concern of the proposed method of analysis and for the sake of simplicity, during testing the circuit in each direction (forward or reverse power transfer) the transistors of the secondary side are bypassed by adding anti-parallel diodes. Fig. 14 shows the experimental set up. The main waveforms are depicted in Fig. 15.

To verify the accuracy of the proposed model, the results coming from the proposed analysis are compared with those of the FHA method, time domain exact simulation by PSIM $®$, and experiments.

\section{A. Output and Control Plane Characteristics}

Fig. 16 compares the control plane characteristics obtained from the state-plane analysis, FHA method, simulation, and experiment results when the switching frequency changes

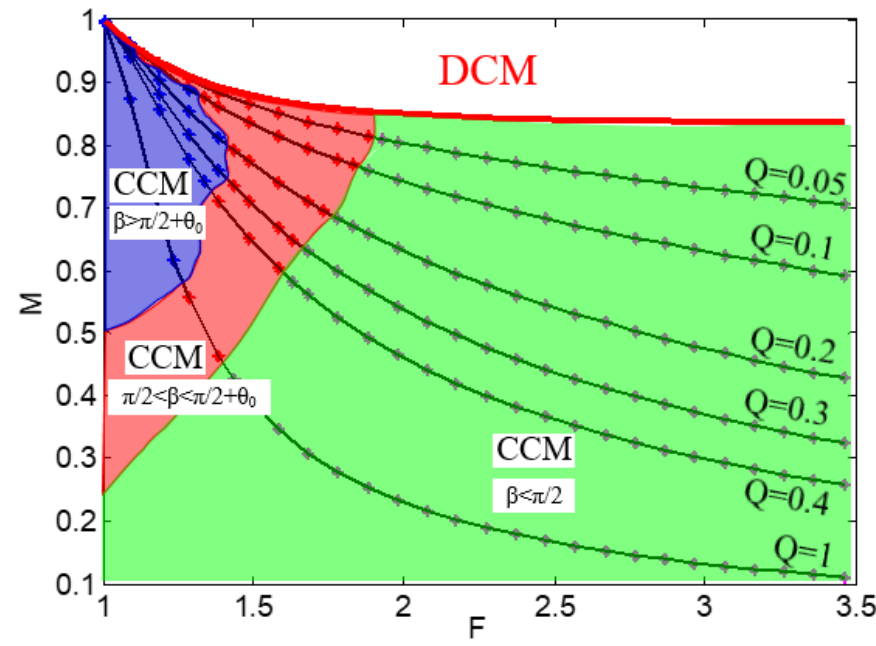

Fig. 12. Control plane diagram (M-F) with $\mathrm{CCM} / \mathrm{DCM}$ boundaries for different values of $Q$.

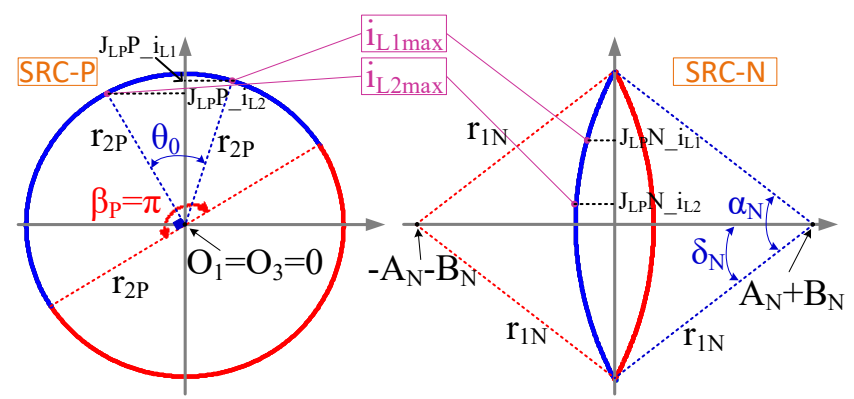

Fig. 13. Control plane diagram (M-F) with $\mathrm{CCM} / \mathrm{DCM}$ boundaries for different values of $Q$.

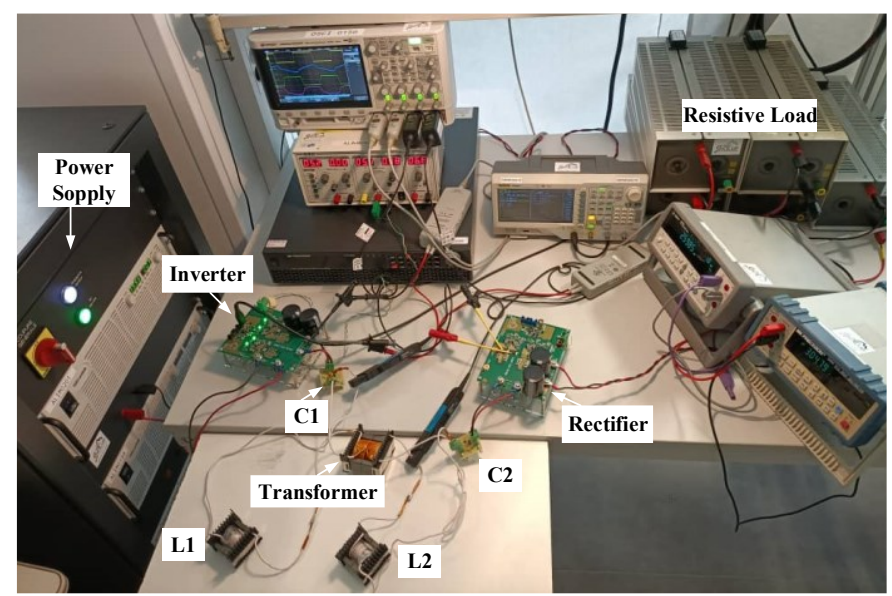

Fig. 14. The experimental set up including the prototype $3 \mathrm{~kW}$ bidirectional CLLC resonant converter.

from $101 \mathrm{kHz}(\mathrm{F}=1)$ to $350 \mathrm{kHz}(\mathrm{F}=3.45)$, and the output power is varied between $430 \mathrm{~W}$ and $1500 \mathrm{~W}$. As can be seen the results from the proposed method are well matched with the simulation and experimental results. It can also be seen that, the gain voltage predicted by FHA is substantially higher than the actual value, which means that care should be taken when the FHA method is used for design and optimization of CLLC converter. The proposed analysis gives exact values of voltage and current of the components and can improve the 


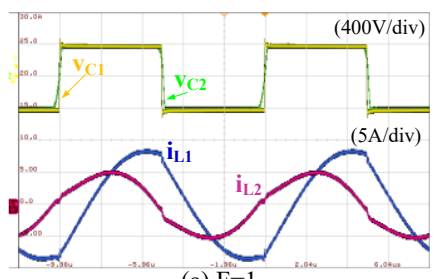

(a) $\mathrm{F}=1$

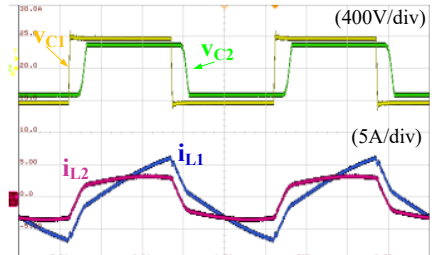

(c) $\mathrm{F}=2$

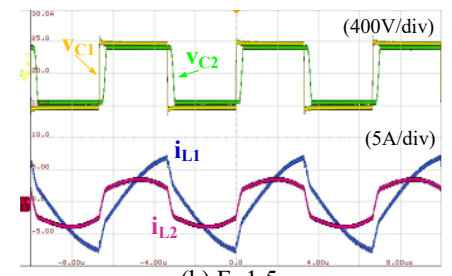

(b) $\mathrm{F}=1.5$

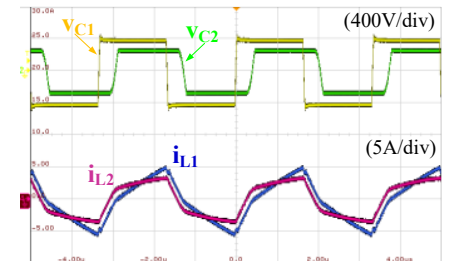

(b) $\mathrm{F}=3$
Fig. 15. Experimental waveforms of CLLC resonant converter in CCM for (a) $\mathrm{F}=1, \mathrm{P}_{\text {out }}=1.2 \mathrm{~kW}$, (b) $\mathrm{F}=1.5, \mathrm{P}_{\text {out }}=960 \mathrm{~W}$, (c) $\mathrm{F}=2, \mathrm{P}_{\text {out }}=790 \mathrm{~W}$, and (d) $\mathrm{F}=3, \mathrm{P}_{\text {out }}=570 \mathrm{~W}$.

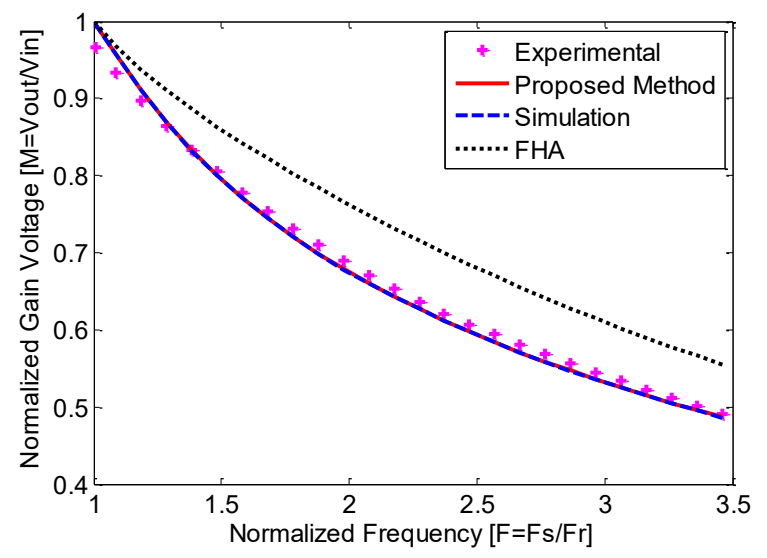

Fig. 16. M-F diagram of the CLLC resonant converter.

power losses estimation and design optimization [31].

In Fig. 17, the output characteristic for $\mathrm{f}_{\mathrm{sw}}=150 \mathrm{kHz}$ and $\mathrm{P}_{\text {out }}=0.9 \sim 1.5 \mathrm{~kW}$ are compared. The results based on the proposed state-plane analysis are consistent with experimental and simulation results in a wide range of load variation, in contrary to those of the FHA method.

\section{B. Maximum Current and Voltage of Resonant Elements}

As previously explained, depending on $\beta_{P}$ there are three possible trajectories that determine the peak inductors current accordingly. Fig. 18 shows waveforms for the forward power transfer operation at three operating points corresponding to each type of trajectory. The peak values obtained by the proposed analysis are perfectly matched with the experimental results and the exact circuit simulation. The peak values predicted by the FHA analysis however are lower than the actual values which can lead to improper selection of the components. Fig. 19 shows the reverse power transfer operation of the CLLC resonant converter at $\mathrm{F}=1$ and $\mathrm{F}=2$.

\section{Soft Switching Condition}

Fig. 20 shows the voltage across a primary side transistor and the corresponding gate signal for minimum dead-time that

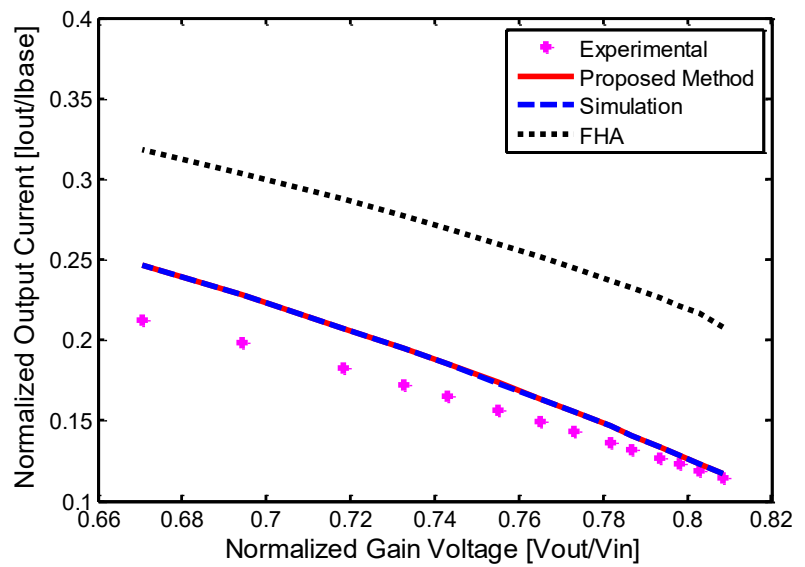

Fig. 17. M-J diagram of the CLLC resonant converter.

TABLE V

\begin{tabular}{|c|c|c|c|}
\hline PARAMETER & VALUE & PARAMETER & VALUE \\
\hline S1 S8 & GS66508B GaN & L1 & $25 \mu \mathrm{H}$ \\
\hline D1 D8 & C4D10120 SiC & L2 & $25 \mu \mathrm{H}$ \\
\hline $\mathrm{C} 1$ & $99 \mathrm{nF}$ & $\mathrm{Lm}$ & $125 \mu \mathrm{H}$ \\
\hline $\mathrm{C} 2$ & $99 \mathrm{nF}$ & Vout & $250 \sim 400 \mathrm{~V}$ \\
\hline $\mathrm{C}_{\mathrm{O}}$ & $220 \mu \mathrm{F}$ & Vin & $400 \mathrm{~V}$ \\
\hline $\mathrm{n}$ & $1: 1$ & $\mathrm{f}_{\mathrm{sw}}$ & $90 \sim 350 \mathrm{kHz}$ \\
\hline
\end{tabular}

ensures ZVS (Eq. (43)). In this figure, the voltage and current waveforms of a secondary side rectifier diodes are also shown, where the secondary side diodes are turned OFF in ZCS condition. Fig. 21 shows the simulation waveform of the switch voltage when the dead-time is set at the minimum value as in (43). As can be seen if a smaller value is applied to $t_{d t}$ the ZVS will be lost.

\section{Boundary and DCM Operating}

Investigating the constraint of (56) shows that a $\mathrm{CCM}$ to DCM transition happens at $F=1.3$ and $Q=0.0356$. Fig. 22 compares the secondary side current, $i_{L 2}$, obtained by circuit simulation and the proposed state space equations. Obviously the circuit simulation confirms operation of the circuit in the boundary condition which is expected by the proposed stateplane analysis. Further decreasing the load current causes the converter to operate in DCM. Fig. 23 depicts experimental results showing DCM operation at $0.6 \mathrm{~A}$ (corresponding to $\mathrm{Q}=$ 0.0239 ) with $\mathrm{M}=0.9953$.

\section{E. General Comparisons}

Table VI compares the results obtained from the proposed state-plane analysis, exact circuit simulation, and the FHA method for two operating points, when the converter operates in the forward power transfer mode. In this table the error of a parameter $X$ is defined by:

$$
\text { Error }=\frac{\left|X_{\text {MEASUREMENT }}-X\right|}{X_{\text {MEASUREMENT }}} \times 100 \%
$$




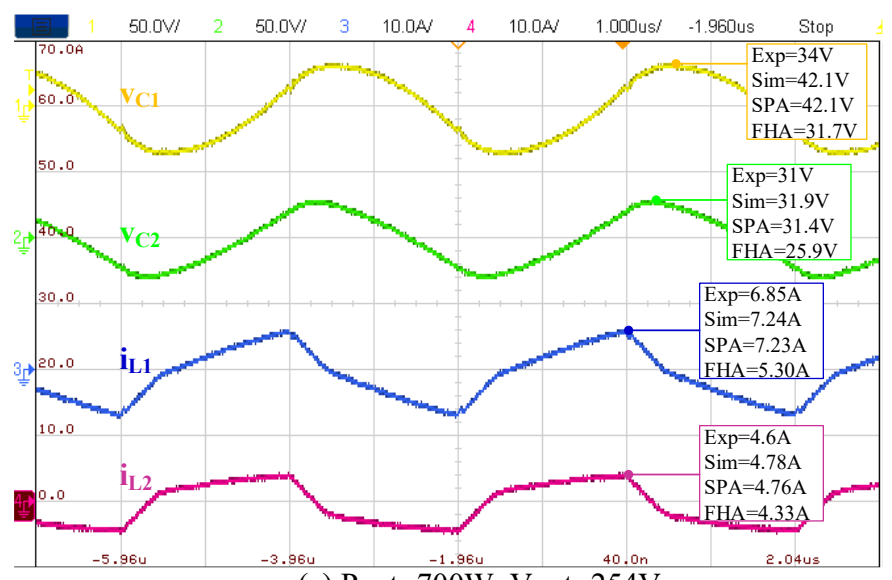

(a) Pout $=700 \mathrm{~W}$, Vout $=254 \mathrm{~V}$

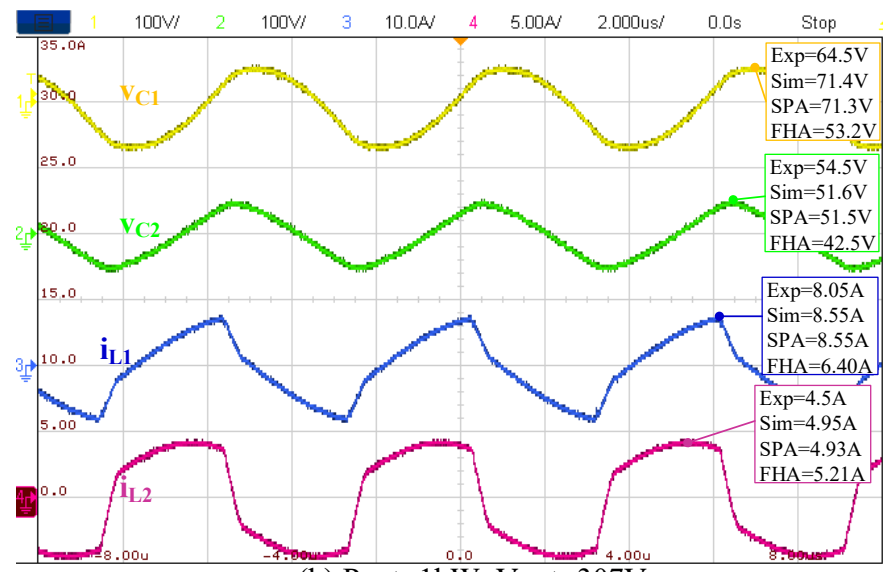

(b) Pout $=1 \mathrm{~kW}$, Vout $=307 \mathrm{~V}$

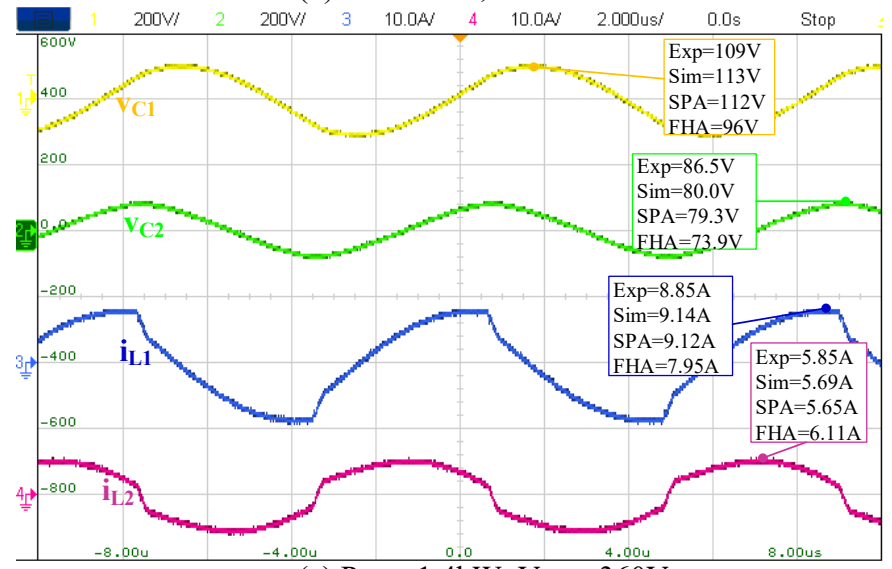

(c) Pout $=1.4 \mathrm{~kW}$, Vout $=360 \mathrm{~V}$

Fig. 18. Current and voltage waveforms of the resonant elements for the forward power transferring under different conditions: (a) $\pi / 2<\beta_{\mathrm{P}}$ at $\mathrm{P}_{\text {out }}=700$ $\mathrm{W}, \mathrm{V}_{\text {out }}=254 \mathrm{~V}, \mathrm{f}_{\mathrm{sw}}=250 \mathrm{kHz}$, (b) $\pi / 2<\beta_{\mathrm{P}}<\theta_{0}$ at $\mathrm{P}_{\text {out }}=1 \mathrm{~kW}, \mathrm{~V}_{\text {out }}=307 \mathrm{~V}, \mathrm{f}_{\mathrm{sw}}$ $=170 \mathrm{kHz}$, and (c) $\beta_{\mathrm{P}}>\pi / 2+\theta_{0}$ at $\mathrm{P}_{\text {out }}=1.4 \mathrm{~kW}, \mathrm{~V}_{\text {out }}=360 \mathrm{~V}, \mathrm{f}_{\mathrm{sw}}=120 \mathrm{kHz}$. Time domain representation are the experimental results. Numbers on the box are comparison between the peak values for experiments, simulations, stateplane analysis, and FHA method. For the FHA method, $\mathrm{f}_{\mathrm{sw}}$ is $268.5 \mathrm{kHz}, 193$ $\mathrm{kHz}$, and $132.8 \mathrm{kHz}$ respectively.

According to Table VI, with the same power and voltage in the forward power transfer mode, all the values resulted from the proposed analysis are well matched with the experimentally measured values, and the errors are much lower than those obtained from on FHA. For example for

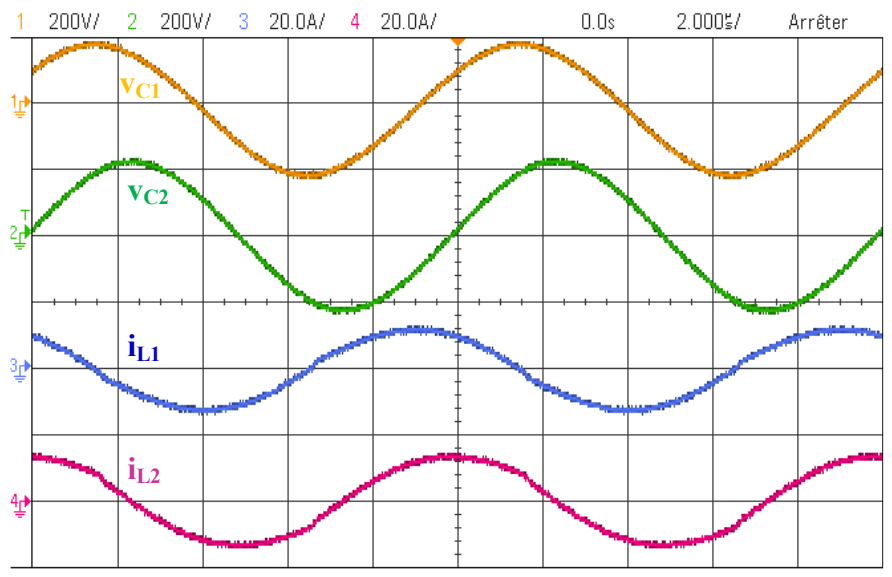

(a) Pout $=3025 \mathrm{~W}$, Vout $=385 \mathrm{~V}$

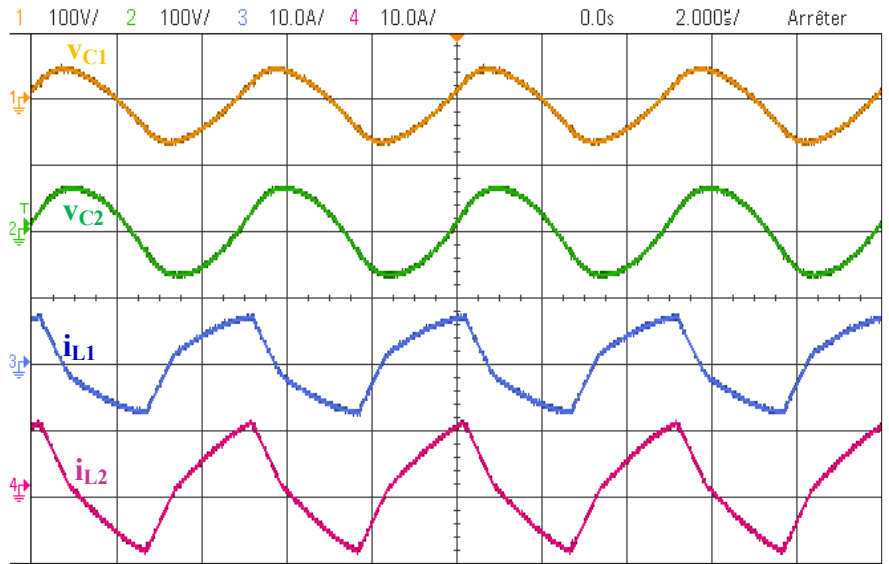

(b) Pout $=918 \mathrm{~W}$, Vout $=212.5 \mathrm{~V}$

Fig. 19. Current and voltage waveforms of the resonant elements for the reverse power transfer mode under different conditions: (a) $\mathrm{P}_{\text {out }}=3025 \mathrm{~W}, \mathrm{~V}_{\text {out }}$ $=385 \mathrm{~V}, \mathrm{f}_{\mathrm{sw}}=100 \mathrm{kHz}$, (b) $\mathrm{P}_{\text {out }}=918 \mathrm{~W}, \mathrm{~V}_{\text {out }}=212.5 \mathrm{~V}, \mathrm{f}_{\mathrm{sw}}=200 \mathrm{kHz}$.

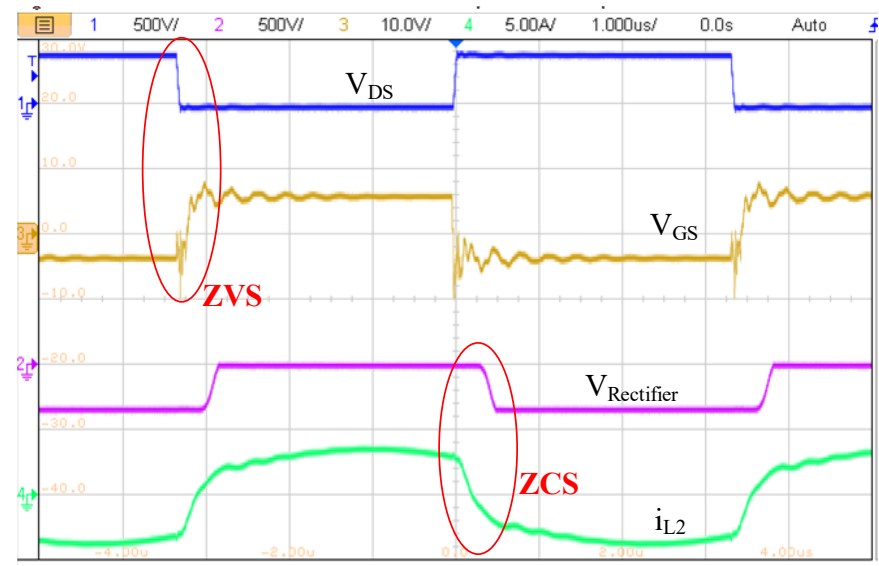

Fig. 20. Waveforms corresponding to minimum dead-time that ensures ZVS and $\mathrm{ZCS}$ on the rectifier.

$i_{L I \max }$, the error of the value obtained from SPA is $2.03 \%$ while the error of the value given by FHA is $15.59 \%$. Also, for $v_{\text {CImax }}$ the errors are $5.16 \%$ and $14.73 \%$ for SPA and FHA respectively. The experimental results of the reverse power transfer mode, are also tabulated in Table VII. Comparing the results of the proposed analysis with the experimental and simulation results, shows that the proposed analysis is also 
IEEE POWER ELECTRONICS REGULAR PAPER/LETTER/CORRESPONDENCE

TABLE VI

Comparison of the Measurement (Meas.), PSim Simulation (Sim.), State-Plane Analysis (SPA), and First Harmonic Approximation (FHA) RESULTS FOR FORWARD POWER TRANSFER

\begin{tabular}{|c|c|c|c|c|c|c|c|c|c|c|c|c|c|c|}
\hline \multirow{3}{*}{ PARAMETER } & \multicolumn{7}{|c|}{ POWER $=1281 \mathrm{~W}$} & \multicolumn{7}{|c|}{ POWER $=527 \mathrm{~W}$} \\
\hline & \multirow{2}{*}{$\frac{\text { MeAs. }}{\text { Value }}$} & \multicolumn{2}{|c|}{ SIM. } & \multicolumn{2}{|c|}{ SPA } & \multicolumn{2}{|c|}{ FHA } & \multirow{2}{*}{$\frac{\text { MeAs. }}{\text { Value }}$} & \multicolumn{2}{|c|}{ SIM. } & \multicolumn{2}{|c|}{ SPA } & \multicolumn{2}{|c|}{ FHA } \\
\hline & & Value & Error & Value & Error & Value & Error & & Value & Error & Value & Error & Value & Error \\
\hline Vout [V] & 347.3 & 347.3 & 0.00 & 347.3 & 0.00 & 347.3 & 0.00 & 216.8 & 216.8 & 0.00 & 216.8 & 0.00 & 216.8 & 0.00 \\
\hline Iout [A] & 3.69 & 3.69 & 0.00 & 3.69 & 0.00 & 3.69 & 0.00 & 2.43 & 2.43 & 0.00 & 2.43 & 0.00 & 2.43 & 0.00 \\
\hline fsw [kHz] & 130.2 & 129.3 & 0.69 & 129.3 & 0.69 & 146 & 12.14 & 298 & 272 & 8.72 & 272 & 8.72 & 330 & 10.74 \\
\hline iL1max [A] & 8.85 & 9.07 & 2.49 & 9.03 & 2.03 & 7.47 & 15.59 & 6.05 & 6.35 & 4.96 & 6.35 & 4.96 & 4.63 & 23.47 \\
\hline iL2max [A] & 5.15 & 5.46 & 6.02 & 5.43 & 5.44 & 5.80 & 12.62 & 4.4 & 4.55 & 3.41 & 4.55 & 3.41 & 3.82 & 13.18 \\
\hline VC1max [V] & 96.5 & 102.91 & 6.64 & 101.48 & 5.16 & 82.29 & 14.73 & 27 & 28.85 & 6.85 & 29.30 & 8.51 & 22.58 & 16.37 \\
\hline $\mathrm{vC} 2 \mathrm{max}[\mathrm{V}]$ & 78.5 & 72.58 & 7.54 & 72.09 & 8.16 & 63.85 & 18.66 & 23 & 22.76 & 1.04 & 22.57 & 1.87 & 18.61 & 19.09 \\
\hline
\end{tabular}

TABLE VII

Comparison of the Measurement (Meas.), PSim Simulation (Sim.), State-Plane ANalysis (SPA), and First Harmonic Approximation (FHA) RESULTS FOR REVERSE POWER TRANSFER

\begin{tabular}{|c|c|c|c|c|c|c|c|c|c|c|c|c|c|c|}
\hline \multirow{3}{*}{ PARAMETER } & \multicolumn{7}{|c|}{ POWER $=3025 \mathrm{~W}$} & \multicolumn{7}{|c|}{ POWER $=918 \mathrm{~W}$} \\
\hline & \multirow{2}{*}{$\frac{\text { MEAS. }}{\text { Value }}$} & \multicolumn{2}{|c|}{ SIM. } & \multicolumn{2}{|c|}{ SPA } & \multicolumn{2}{|c|}{ FHA } & \multirow{2}{*}{$\frac{\text { MeAs. }}{\text { Value }}$} & \multicolumn{2}{|c|}{ SIM. } & \multicolumn{2}{|c|}{ SPA } & \multicolumn{2}{|c|}{ FHA } \\
\hline & & Value & Error & Value & Error & Value & Error & & Value & Error & $\overline{\text { Value }}$ & Error & $\overline{\text { Value }}$ & Error \\
\hline Vout [V] & 385 & 385 & 0.00 & 385 & 0.00 & 385 & 0.00 & 212.5 & 212.5 & 0.00 & 212.5 & 0.00 & 212.5 & 0.00 \\
\hline Iout [A] & 7.85 & 7.85 & 0.00 & 7.85 & 0.00 & 7.85 & 0.00 & 4.32 & 4.32 & 0.00 & 4.32 & 0.00 & 4.32 & 0.00 \\
\hline fsw [kHz] & 105 & 107.4 & 2.28 & 107.5 & 2.28 & 110 & 4.76 & 199.5 & 196.9 & 1.30 & 196.9 & 1.30 & 220.5 & 10.53 \\
\hline iL1max [A] & 14.17 & 13.99 & 1.27 & 13.93 & 1.69 & 13.92 & 1.76 & 9.76 & 10.13 & 3.79 & 10.11 & 3.59 & 8.02 & 17.83 \\
\hline iL2max [A] & 11.76 & 11.93 & 1.44 & 11.89 & 1.10 & 12.33 & 4.85 & 7.09 & 7.67 & 8.18 & 7.65 & 7.90 & 6.79 & 4.23 \\
\hline $\mathrm{VC} 1 \mathrm{max}[\mathrm{V}]$ & 226.50 & 216.5 & 4.41 & 217.13 & 4.13 & 203.43 & 10.18 & 65.04 & 66.82 & 2.74 & 67.25 & 3.40 & 58.51 & 10.04 \\
\hline $\mathrm{vC} 2 \max [\mathrm{V}]$ & 185.33 & 184.75 & 0.31 & 184.55 & 0.42 & 180.23 & 2.75 & 58.44 & 55.55 & 4.94 & 55.45 & 5.11 & 49.56 & 15.19 \\
\hline
\end{tabular}

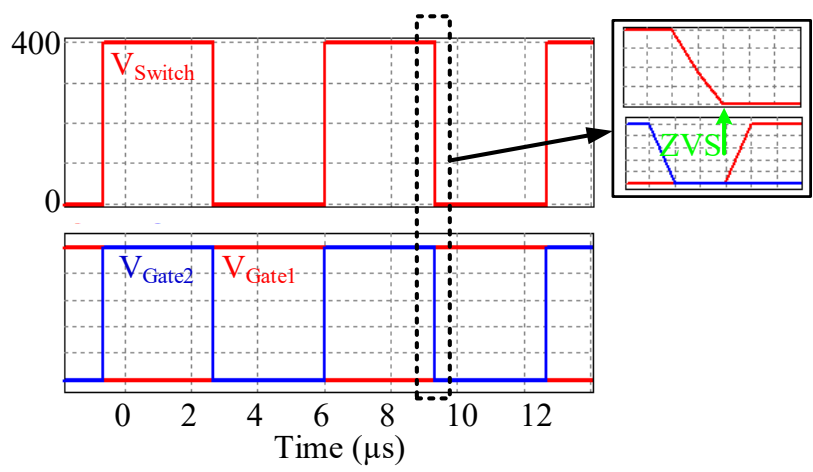

Fig. 21. Simulation of minimum dead-time (boundary condition) for gate pulses and the switch voltage to ensure ZVS.

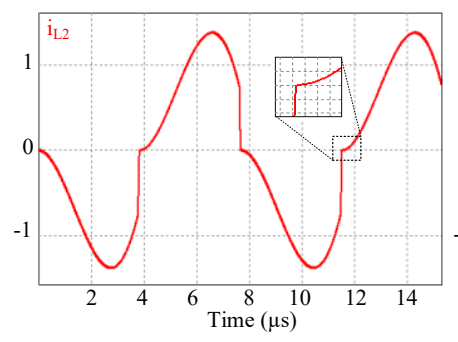

(a)

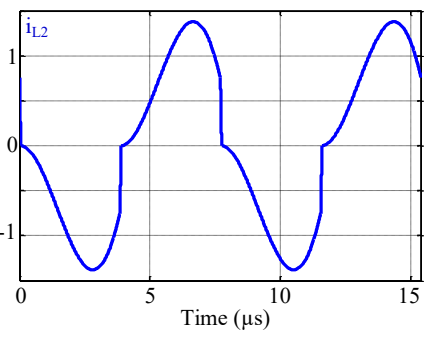

(b)
Fig. 22. The secondary side current in the boundary condition by; (a) simulation, and (b) state-plane analysis.

effective for the reverse power transfer operation. Fig. 24 shows that the maximum efficiency of the converter operating in forward power transfer is $95.72 \%$ while it is $95.62 \%$ for the reverse power transfer.

As a conclusion, it can be deduced that the proposed method has much higher precision in comparison with the FHA method for both power transferring directions. This exact

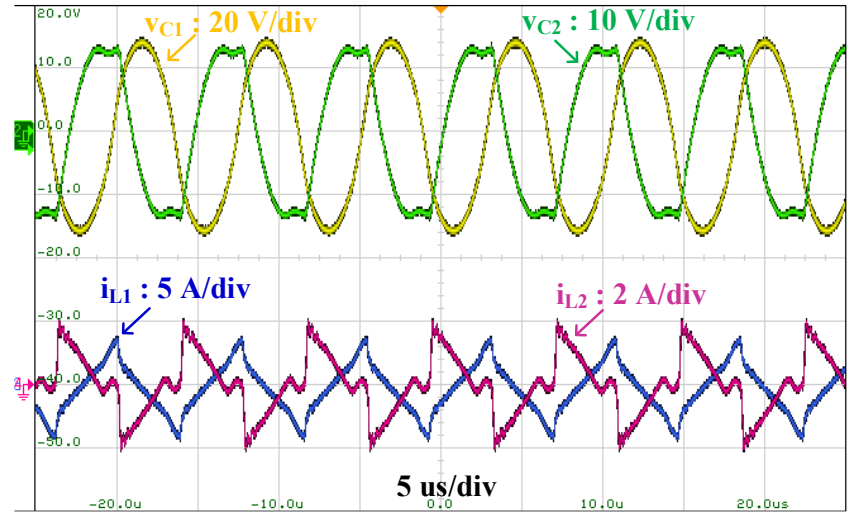

Fig. 23. Experimental test in the DCM operating.

analysis can be used in design, control, and optimization of the CLLC resonant converter as well as other high-order resonant converters. Owing to mathematical expression of the converter behavior, this method is very helpful for practicing optimization algorithms to minimize voltage/current stresses, and losses as well as reliability assessment.

\section{CONCLUSION}

This paper proposed in detail the state-plane analysis of the bidirectional full-bridge CLLC resonant converter for the switching above the resonant frequency. A new formulation of state-space equations was presented and the fourth-order CLLC resonant converter was transformed into two secondorder systems. Then using this mathematical method, the exact analysis of converter in CCM, stresses of the components, voltage gain ratio, soft switching conditions, and boundary 


\section{IEEE POWER ELECTRONICS REGULAR PAPER/LETTER/CORRESPONDENCE}

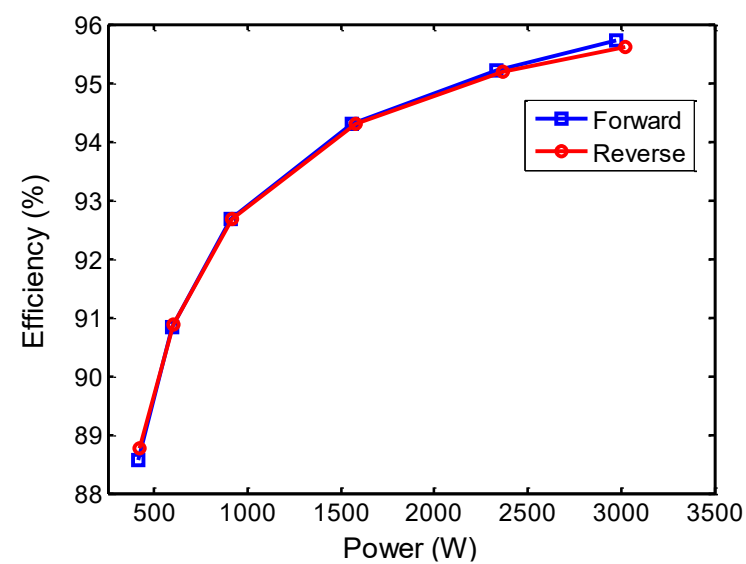

Fig. 24. Efficiency for the forward and reverse power transferring.

between $\mathrm{CCM} / \mathrm{DCM}$ were obtained. A $3 \mathrm{~kW}$ prototyping was built. Experimental results were used to verify the proposed method. Simulation and experimental results reveal the accuracy of the proposed analysis in the forward and the reverse power transfer modes for different power and voltage levels. The proposed state-plane analysis helpful in design and optimizing of the CLLC resonant converter in a wide operating range.

\section{APPENDIX}

By substituting $i_{L 1}, i_{L 2}^{\prime}, v_{C l}$, and $v_{C 2}^{\prime}$ as the function of $i_{L P}$, $i_{L N}, v_{C P}$, and $v_{C N}$ according to (4) into (2) and rearranging them, the state space equations are recalculated as:

$$
\begin{aligned}
\frac{d v_{C P}}{d t}= & \frac{1}{a_{P}+a_{N}}\left(\left(\frac{e_{P}}{C_{1}}+\frac{a_{N}}{C^{\prime}{ }_{2}}\right) i_{L P}+\left(\frac{e_{P}}{C_{1}}-\frac{a_{P}}{C^{\prime}}\right) i_{2 N}\right) \\
\frac{d i_{L P}}{d t}= & \frac{-1}{\Gamma\left(e_{P}+e_{N}\right)}\left\{\left(a_{P}\left(L^{\prime}{ }_{2}+L_{m}\right)+L_{m}+L_{m} e_{N} a_{P}+e_{N}\left(L_{1}+L_{m}\right)\right) v_{C P}\right. \\
& \left.+\left(a_{P}\left(L_{2}^{\prime}+L_{m}\right)+L_{m}-L_{m} e_{P} a_{P}-e_{P}\left(L_{1}+L_{m}\right)\right) v_{C N}\right\} \\
& -\frac{L_{m}+a_{P} L_{m}+a_{P} L_{2}^{\prime}}{\Gamma} v_{1}-\frac{L_{m}+a_{P} L_{m}+L_{1}}{\Gamma} v^{\prime}{ }_{2} \\
\frac{d v_{C N}}{d t} & =\frac{1}{a_{P}+a_{N}}\left(\left(\frac{e_{N}}{C_{1}}-\frac{a_{N}}{C^{\prime}{ }_{2}}\right) i_{L P}+\left(\frac{e_{N}}{C_{1}}+\frac{a_{P}}{C^{\prime}{ }_{2}}\right) i_{L N}\right) \\
\frac{d i_{L N}}{d t}= & \frac{-1}{\Gamma\left(e_{P}+e_{N}\right)}\left\{\left(a_{N}\left(L_{2}^{\prime}{ }_{2}+L_{m}\right)-L_{m}+L_{m} e_{N} a_{N}-e_{N}\left(L_{1}+L_{m}\right)\right) v_{C P}\right. \\
& \left.+\left(a_{N}\left(L_{2}^{\prime}+L_{m}\right)-L_{m}-L_{m} e_{P} a_{N}+e_{P}\left(L_{1}+L_{m}\right)\right) v_{C N}\right\} \\
& -\frac{a_{N} L_{2}^{\prime}+a_{N} L_{m}-L_{m}}{\Gamma} v_{1}-\frac{a_{N} L_{m}-L_{m}-L_{1}}{\Gamma} v^{\prime}
\end{aligned}
$$

For decoupling the parameters $\mathrm{P}$ and $\mathrm{N}$, it is mandatory to put the coefficients of unwanted parameters to zero. For (58) and (59), the coefficients of $i_{L N}$ and $v_{C N}$, and for (60) and (61), the coefficients of $i_{L P}$ and $v_{C P}$ must be set equal to zero:

$$
\begin{aligned}
& \frac{e_{P}}{C_{1}}-\frac{a_{P}}{C_{2}^{\prime}}=0 \\
& a_{P}\left(L_{2}^{\prime}{ }_{2}+L_{m}\right)+L_{m}-L_{m} e_{P} a_{P}-e_{P}\left(L_{1}+L_{m}\right)=0 \\
& \frac{e_{N}}{C_{1}}-\frac{a_{N}}{C^{\prime}{ }_{2}}=0 \\
& a_{N}\left(L_{2}^{\prime}+L_{m}\right)-L_{m}+L_{m} e_{N} a_{N}-e_{N}\left(L_{1}+L_{m}\right)=0
\end{aligned}
$$

By solving (62), the parameters $a_{P}, a_{N}, e_{P}$, and $e_{N}$ are obtained as shown in (5).

\section{REFERENCES}

[1] S. Zhao, Q. Li, F.C. Lee, and B. Li, "High-frequency transformer design for modular power conversion from medium-voltage AC to 400 VDC," IEEE Trans. Power Electronics, vol. 33, pp. 7545-7557, October 2017.

[2] M.H. Ryu, H.S. Kim, J.H. Kim, J.W. Baek, and J.H. Jung, "Test bed implementation of $380 \mathrm{~V}$ DC distribution system using isolated bidirectional power converters," In Proc. IEEE Energy Conversion Congress and Exposition Conf., 2013, pp. 2948-2954.

[3] Z. Zhang, C. Liu, M. Wang, Y. Si, Y. Liu, and Q. Lei, "High-efficiency high-power-density CLLC resonant converter with low-straycapacitance and well-heat-dissipated planar transformer for EV on-board charger," IEEE Trans. Power Electronics, vol. 35, pp. 10831-10851, Mars 2020.

[4] J. Min, and M. Ordonez, "Bidirectional Resonant CLLC Charger for Wide Battery Voltage Range: Asymmetric Parameters Methodology," IEEE Trans. Power Electronics, vol. 36, pp. 6662-6673, June 2021.

[5] C. Liu, J. Wang, K. Colombage, C. Gould, and B. Sen, "A CLLC resonant converter based bidirectional EV charger with maximum efficiency tracking," in Proc. IET International Conference on Power Electronics, Machines and Drives (PEMD), 2016, pp. 1-6.

[6] M.H. Ryu, H.S. Kim, J.W. Baek, H.G. Kim, and J.H. Jung, "Effective test bed of $380-\mathrm{V}$ DC distribution system using isolated power converters" IEEE Trans. Industrial Electronics, vol. 62, pp. 4525-4536, February 2015.

[7] J. Huang, J. Xiao, C. Wen, P. Wang, and A. Zhang, "Implementation of bidirectional resonant DC transformer in hybrid AC/DC micro-grid," IEEE Trans. Smart Grid, vol. 10, pp. 1532-1542, November 2017.

[8] S. Zou, J. Lu, A. Mallik, A. Khaligh, "Bi-directional CLLC converter with synchronous rectification for plug-in electric vehicles," IEEE Trans. Industry Applications, vol. 54, pp. 998-1005, November 2017.

[9] S. Endres, C. Sessler, S. Zeltner, B. Eckardt, and T. Morita, " $6 \mathrm{~kW}$ Bidirectional, Insulated On-board Charger with Normally-Off GaN Gate Injection Transistors," in Proc. International Exhibition and Conference for Power Electronics, Intelligent Motion, Renewable Energy and Energy Management (PCIM), 2017, pp. 1-6.

[10] W. Chen, P. Rong, and Z. Lu, "Snubberless bidirectional DC-DC converter with new CLLC resonant tank featuring minimized switching loss," IEEE Trans. Industrial Electronics, vol. 57, pp. 3075-3086, December 2009.

[11] J.H. Jung, H.S. Kim, M.H. Ryu, and J.W. Baek, "Design methodology of bidirectional CLLC resonant converter for high-frequency isolation of DC distribution systems," IEEE Trans. Power Electronics, vol. 28, pp. 1741-1755, August 2012.

[12] P. He, and A. Khaligh, "Comprehensive analyses and comparison of 1 $\mathrm{kW}$ isolated DC-DC converters for bidirectional EV charging systems," IEEE Trans. Transportation Electrification, vol. 3, pp. 147-156, November 2016.

[13] R.L. Steigerwald, "A comparison of half-bridge resonant converter topologies," IEEE Trans. Power Electronics, vol. 3, pp. 174-182, April 1988.

[14] C. Zhang, P. Li, Z. Kan, X. Chai, and X. Guo, "Integrated half-bridge CLLC bidirectional converter for energy storage systems," IEEE Trans. Industrial Electronics, vol. 65, pp. 3879-3889, October 2017.

[15] A. Safaee A, and K. Woronowicz, "Time-domain analysis of voltagedriven series-series compensated inductive power transfer topology," IEEE Trans. Power Electronics, vol. 32, pp. 4981-5003, December 2016.

[16] Y. Wei, Q. Luo, X. Du, N. Altin, J.M. Alonso, and H.A. Mantooth, "Analysis and design of the LLC resonant converter with Variable inductor control based on time-domain analysis," IEEE Trans. Industrial Electronics, vol. 67, pp. 5432-5443, August 2019.

[17] R. Oruganti, and F.C. Lee, "Resonant power processors, Part I---State plane analysis," EEE Trans. Industry Applications, vol. 1, pp. 14531460, November 1985

[18] H. Chen, E.K. Sng, and K.J. Tseng, "Generalized optimal trajectory control for closed loop control of series-parallel resonant converter," 
IEEE Trans. Power Electronics, vol. 21, pp. 1347-1355, September 2006.

[19] V. Anand, A. Pal, B. Kuchibhatla, R. Gurunathan, and K. Basu, "An Unidirectional Single Stage Single Phase Soft-Switched Resonant High Frequency Link Inverter," IEEE Trans. Industry Applications, vol. 57, pp. 3238-3251, April 2021.

[20] T.N. Gücin, B. Fincan B, and M. Biberoğlu, "A series resonant converter-based multichannel led driver with inherent current balancing and dimming capability," IEEE Trans. Power Electronics, vol. 34, pp. 2693-2703, May 2018.

[21] Y. Xu, C. Lu, Z. Yu, J. Chen, S. Xu, Y. Wang, and X. He, "Multi-mode Constant Power Control Strategy for LCC Resonant Capacitor Charging Power Supply Based on State Plane Analysis," IEEE Trans. Power Electronics, vol. 36, pp. 8399-8412, July 2021.

[22] I.G. Zurbriggen, F. Degioanni, and M. Ordonez, "Near time optimal dynamics in PWM DC-DC converters: Dual-loop geometric control," IEEE Journal of Emerging and Selected Topics in Power Electronics, vol. 9, pp. 167-182, February 2021.

[23] R. Barrero, O. Hegazy, J. Van Mierlo, P. Lataire, and T. Coosemans, “A modified state-plane control of a bi-directional Series Resonant Converter for an EDLC Energy Storage System in Hybrid Electric Vehicles," in Proc. European Conference on Power Electronics and Applications, 2014 pp. 1-12.

[24] Z.U. Zahid, Z.M. Dalala, R. Chen, B. Chen, and J.S. Lai, "Design of bidirectional DC-DC resonant converter for vehicle-to-grid (V2G) applications," IEEE Trans. Transportation Electrification, vol. 1, pp. 232-244, September 2015.

[25] S. Ditze, "Steady-state analysis of the bidirectional CLLLC resonant converter in time domain," in Proc. International Telecommunications Energy Conference (INTELEC), 2014, pp. 1-9.

[26] Z. Lv, X. Yan, Y. Fang, and L. Sun, "Mode analysis and optimum design of bidirectional CLLC resonant converter for high-frequency isolation of DC distribution systems," in Proc. Energy Conversion Congress and Exposition (ECCE) Conf., 2015, pp. 1513-1520.

[27] B. Li, F.C. Lee, Q. Li, and Z. Liu, "Bi-directional on-board charger architecture and control for achieving ultra-high efficiency with wide battery voltage range," in Proc. Applied Power Electronics Conference and Exposition (APEC), 2017, pp. 3688-3694.

[28] W.L. Malan, D.M. Vilathgamuwa, and G.R. Walker, "Modeling and control of a resonant dual active bridge with a tuned CLLC network," IEEE Trans. Power Electronics, vol. 31, pp. 7297-7310, December 2015.

[29] H.S. Kim, M.H. Ryu, J.W. Baek, and J.H. Jung, "High-efficiency isolated bidirectional AC-DC converter for a DC distribution system," IEEE Trans. Power Electronics, vol. 28, pp. 1642-1654, August 2012.

[30] R. Zheng, B. Liu, and S. Duan, "Analysis and parameter optimization of start-up process for LLC resonant converter," IEEE Trans. on Power Electronics, vol. 30, pp. 7113-7122, January 2015.

[31] M. Rezayati, J.L. Schanen, F. Tahami, and B. Sarrazin, "InterpolationBased Switching and Conduction Losses Model of GaN Transistors," in Proc. Annual Conference of the IEEE Industrial Electronics Society (IECON), 2020, pp. 1353-1358.

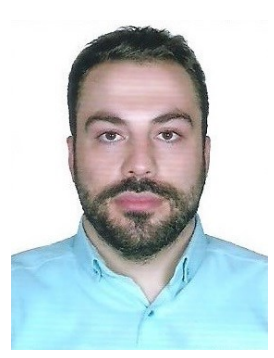

Mohsen Rezayati received the B.S. degree (Hons.) from Shahid Beheshti University, Tehran, Iran, and the M.S. degree from Sharif University of Technology, Tehran, Iran, in 2014 and 2016, respectively, all in electrical engineering. $\mathrm{He}$ is currently pursuing the Ph.D. degree in power electronics engineering under a dual-degree doctoral program in-between the Department of Electrical Engineering, Sharif University of Technology, Tehran, Iran, and the University of Grenoble Alpes (UGA), Grenoble, France. Since October 2018, he has been a Researcher with the Grenoble Electrical Engineering
Laboratory (G2ELab). His research interests include power electronic converters analysis and design, dc-dc converters optimization, soft-switching and resonant converters, and wide band gap (WBG) devices. He was a recipient of the Best Paper Award in 8th International Power Electronics, Drive Systems and Technologies Conference (PEDSTC) in 2017.

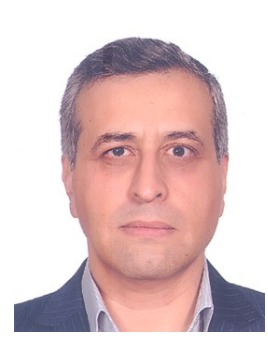

Farzad Tahami (M'97-SM'12) received the B.S. degree in electrical engineering from Ferdowsi University of Mashhad, Mashhad, Iran, in 1991, and the M.S. and $\mathrm{Ph} . \mathrm{D}$. degrees in electrical engineering from the University of Tehran, Tehran, Iran, in 1993 and 2003, respectively. In 2004, he joined Sharif University of Technology, Tehran, Iran, where he is currently an Associate Professor. Dr. Tahami is a Member of the Board of Directors and the Chairman of the education committee of the Power Electronics Society of Iran (PESI). His current research interests include electric motor drives, modeling and control of power electronic converters, design of electric machines, resonant converters, high-frequency power conversion, and wireless power transfer.

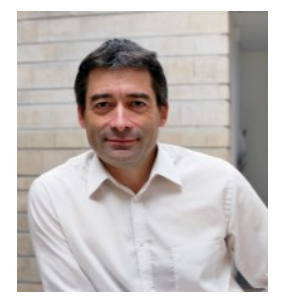

Jean-Luc Schanen (M'99-SM'04) received the Electrical Engineering Diploma and the Ph.D. degrees from the Grenoble Institute of Technology, Grenoble, France, in 1990 and 1994, respectively.

$\mathrm{He}$ is a Professor at University Grenoble Alpes since 2003 and is leading the power electronics research group of G2ELab. His research activities are focused on the technological design of Power Electronics systems, including EMC aspects. His group develops models and tools for Power Converters optimization. Dr. Schanen is an active member of both IEEE-IAS and Power Electronics societies, involved in the organizing committees of several conferences as ECCE, and associate editor of IEEE transactions on IAS and PELS.

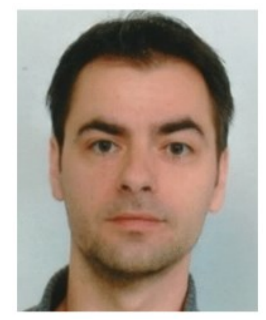

Benoit Sarrazin (Member, IEEE) was born in Grenoble, France. He received the B.S. and M.S. degrees in electrical engineering from the Grenoble INP University of Electrical Engineering, Grenoble, in 2008, and the Ph.D. degree in electrical engineering from Grenoble INP University, Grenoble, in 2012.

From 2012 to 2018, he was a Research Scientist with the Technical Team, Grenoble Electrical Engineering Laboratory (G2Elab), Grenoble, where he has been the Head of the Mechatronics Team, Technical Department, since 2018. 